\title{
Development of poly-vinyl alcohol stabilized silver nanofluids for solar thermal applications
}

\author{
James Walshe \\ Technological University Dublin, james.walshe@tudublin.ie \\ George Amarandei \\ Technological University Dublin, george.amarandei@tudublin.ie \\ Hind Ahmed \\ Technological University Dublin
}

See next page for additional authors

Follow this and additional works at: https://arrow.tudublin.ie/dubenart

Part of the Environmental Engineering Commons, Natural Resources and Conservation Commons, Other Civil and Environmental Engineering Commons, Other Environmental Sciences Commons, Structural Engineering Commons, and the Sustainability Commons

\section{Recommended Citation}

James Walshe, George Amarandei, Hind Ahmed, Sarah McCormack, John Doran, Development of polyvinyl alcohol stabilized silver nanofluids for solar thermal applications, Solar Energy Materials and Solar Cells, Volume 201, 2019, 110085, ISSN 0927-0248, DOI: 10.1016/j.solmat.2019.110085.

This Article is brought to you for free and open access by the Dublin Energy Lab at ARROW@TU Dublin. It has been accepted for inclusion in Articles by an authorized administrator of ARROW@TU Dublin. For more information, please contact arrow.admin@tudublin.ie, aisling.coyne@tudublin.ie,gerard.connolly@tudublin.ie. Funder: Technological University Dublin

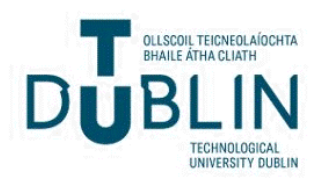




\section{Authors}

James Walshe, George Amarandei, Hind Ahmed, Sarah McCormack, and John Doran 


\title{
Development of poly-vinyl alcohol stabilized silver nanofluids for solar thermal applications
}

\author{
James Walshe ${ }^{\mathrm{a}, \mathrm{b}}$, George Amarandei ${ }^{\mathrm{b}, *}$, Hind Ahmed ${ }^{\mathrm{c}}$, Sarah McCormack ${ }^{\mathrm{c}}$, John Doran ${ }^{\mathrm{a}, \mathrm{b}}$ \\ ${ }^{a}$ Dublin Energy Lab, Technological University Dublin, City Campus, Dublin, Ireland \\ ${ }^{\mathrm{b}}$ School of Physics \& Clinical \& Optometric Sciences, Technological University Dublin, City Campus, Kevin Street, Dublin, Ireland \\ ${ }^{\mathrm{c}}$ Department of Civil, Structural \& Environmental Engineering, Trinity College Dublin, Dublin, Ireland
}

\section{A R T I C L E I N F O}

\section{Keywords:}

Plasmonic

Silver nanoparticle

Solar energy

Photothermal conversion

Nanofluids

\begin{abstract}
A B S T R A C T
Nanofluids offer the potential to address the low thermal conductivities found in conventional heat transfer fluids, through their unique electrical, optical and thermal properties, but their implementation remains restricted due to absorption and stability limitations. Here, we characterize and exploit the distinctive plasmonic properties exhibited by polyvinyl-alcohol stabilized silver nanostructures by tuning their absorption and thermal properties through controlling the nanoparticle size, morphology and particle-size distribution configuration at the synthesis stage. The photo-thermal efficiency of different water-based silver nanofluids under a standard AM1.5G weighted solar spectrum were explored, the influence of each of these components on the resulting fluids performance within a direct absorption solar thermal collection system being considered. Nanofluids, containing an extensive ensemble of particle size-distributions ( $5 \mathrm{~nm}-110 \mathrm{~nm}$ in diameter) in addition to anisotropic particle morphologies (e.g. prisms, hexagons and other non-spherical geometries), exhibited a significant enhancement in the absorption and photo-thermal energy transfer. Enhancements of 5\%-32\% in the photo-thermal conversion efficiency were achieved, the enhancement being dependent upon the presence of multiple particle size-distributions and the particle concentration. The enhancement is influenced by the interactions occurring between the individual particle size-distributions but also by the collective behaviour of the particles ensemble. The critical particle diameter, above which the photo-thermal characteristics of the nanofluid become dominated by the larger sized particles present, was identified as $150 \mathrm{~nm}$. The increased performance of these nanofluids, which adopt a more complex particle-size configuration, suggests that they can represent suitable candidates for solar-thermal applications.
\end{abstract}

\section{Introduction}

Solar energy is one of the renewable sectors which has received considerable interest mainly due to the continuous reduction in costs associated with manufacturing technologies [1-13]. At present, there are two main types of solar energy systems: those reliant on the direct conversion of the incident solar irradiance into usable electricity (solarphotovoltaic) and those based on harnessing the solar irradiance to use it as an alternative source of thermal energy (solar-thermal) to meet a proportion of a buildings cooling and heating demands [14-18]. The implementation and subsequent market penetration of photovoltaic solar based technologies has been mostly confined to the industrial electricity sector. This allowed for the expansion and adoption of the thermal solar technology mainly into the residential environment, where there is a substantial cooling and heating demand [19]. Recently, combined heat-power [20-21] and photovoltaic-thermal hybrid solar systems [22] have started to become suitable alternatives. Thus, two independent systems, photovoltaic and photo-thermal, work in unison to capture and convert a larger proportion of the solar energy available. The two different forms of energy captured can be stored in batteries and using a heat pump, respectively [22]. Larger scale solar combined heat-power systems include concentrating solar power stations, which utilize the concentrating power of a large area of mirrors to collect and focus the sunlight directly onto a target material of high heat capacity. This generates immense thermal energy that can be directly used to generate electricity, or it can be stored to meet a proportion of the energy demand once the sun goes down [20-21].

Typically, in solar thermal plants or in a conventional flat plate solar thermal collection (FPSC) system, the solar radiation captured by a heat sink is in turn transferred to a working fluid (e.g. water, ethylene glycol

\footnotetext{
* Corresponding author.

E-mail address: george.amarandei@dit.ie (G. Amarandei).
} 
etc.) which passes through the enclosed system under flow conditions specific to the application [15-18,22-24]. Therefore, the working fluid plays a dominant role in enhancing the efficiency of the energy transfer, which, in turn, is dependent upon the composition, arrangement, stability and photo-thermal properties of the fluid. Early efforts on improving the photo-thermal conversion efficiency of different working fluids (including water, oils, as well as gaseous media) resulted in neither low costs nor high-energy transfer efficiencies [24,25]. To enhance the physical properties of a working fluid nanometer sized particles can be suspended into a base fluid[26-32,106,107]. The presence of such particles, commonly composed of highly conductive materials, dominate the thermal and physical properties of the resulting fluid $[26,29,33]$. The resulting fluid suspensions, generically called nanofluids or nanosuspensions, have become a leading candidate for the cost reduction of the solar-thermal energy [25,27-28,34].

In recent years, nanofluids have gained considerable interest due to the functionalization and the control over the optical and thermal properties that can be gained through a plethora of fabrication routes. The choice of nanomaterial (composition, size and shape) influences the absorption and thermo-physical properties of the base fluid [4-6,3133,35-36]. Thus, nanoparticles comprised of metal (Ag, Au, Pt, Al and $\mathrm{Cu}$ ), metal oxide $\left(\mathrm{TiO}_{2}, \mathrm{CuO}, \mathrm{Al}_{2} \mathrm{O}_{3}\right)$ and carbon (carbon black, graphite, graphene, and carbon nanotubes) based materials have previously been shown to enhance the conversion efficiency within solarthermal systems [37-42]. Metal oxides nanoparticles, offering thermal conductivities significantly lower than their metal or carbon counterparts, have delivered enhancements in the thermal conductivity of water based nanofluids ranging from $20 \%$ to $52 \%$ at moderate operating temperatures of up to $50^{\circ} \mathrm{C}$ [43-46].

Metal nanoparticles ( $\mathrm{Ag}$ or $\mathrm{Au}$, in particular) have attracted an intense interest because of the localized surface plasmon resonance (LSPR) absorption that typically occurs in the ultraviolet-visible (UV-Vis) part of the spectrum i.e. in the spectral region where most of the incoming solar flux is distributed [47-48]. The UV-VIS spectral region is, typically, weakly absorbed by most of the classical heat transfer fluids and, therefore, adding the nanoparticles will enhance its absorption [47-48]. Silver is of greater interest for solar thermal applications due to its higher thermal conductivity, lower cost and the number of robust synthesis routes available [49-53]. Oscillations within the locally enhanced electromagnetic fields established through the LSPR phenomena enable the absorption characteristics of the structures to be fine-tuned over a specific spectral range, specific to the application [54-57].

The large surface area of the nanoparticles promotes the interactions between the nanoparticles and the additional chemical species present in the nanofluid [27-28,58]. Each particle experiences attractive and repulsive forces [27-28,58] and the delicate balance within a nanofluid between these attractive and repulsive forces determines the tendency of the nanoparticles to clump together via a process called agglomeration, affecting the capability of the fluid to remain stable [27$28,58]$. Typically, the attractive molecular forces are more energetically favourable and, hence, over time, the particles within the two-phase fluid coalesce, forming larger and larger aggregates, destabilising the nanofluid as the process continues [30,59-60]. As the size-distribution of the suspended particles becomes broader through particle-agglomeration, an inherent transformation in the thermal properties of the resulting nanofluid occurs [27-28,58].The susceptibility of nanofluids towards particle-agglomeration as a means of reducing their surface energy can be controlled through modification of the nanoparticles surface chemistry $[40,52-53,61]$.The addition of surfactants or stabilising agents during the nanofluids preparation offers a simple and costeffective route for preparing stable nanofluids [27-28,43,62]. A stabilising agent, typically consisting of a polymeric chain containing hydrophobic and hydrophilic elements at opposite ends of the molecule, selectively binds to the surface of the nanoparticles altering the repulsive forces existing between neighbouring particles within the nanofluid [51,54,61,63]. The long polymeric chain can curtail the transfer of heat between the stabilised nanoparticles and the surrounding solvent molecules $[30,44,53,64]$. Consequently, in the pursuit of highly efficient nanofluids for heat transfer applications, a trade-off between the fluids enhanced thermal properties and its stability is required [26-27,52-53,57,65].

Typically, the nanoparticles utilized in nanofluids studies embodied a single mode narrow-distribution of the particle size [39-42]. However, using a poly-disperse particle size-distribution can influence the interaction between the collective ensembles of particles and promote the thermal properties of the base fluid. Within such a wide-ranging particle size-distribution, the larger sized particles form an antenna effectively coupling the higher order LSPR modes available on these nanostructures to the nearby smaller size particles. These smaller size particles can in turn act as resonators, creating localized 'hot-spot' regions [48,66-69]. The enhanced electric field established through such an interconnected particle network is greater in magnitude than that created through isolated narrow particle size-distributions [66-69]. Typically, the commercially purchased nanoparticles employed in the design and characterization of nanofluids are lacking in the variety of particle morphologies, shapes and sizes [37,39,50,70-71]. This can be mainly due to the product control existing within a commercial environment, which requires narrow particle size-distributions and similar morphologies for the nanoparticles as a commercial product. Consequentially, in the research pursuit of efficient and stable nanofluids, the possibility of particle-particle interactions between different anisotropic shape and sizes has been, typically, overlooked. However, such interactions can have the potential of enhancing the absorption and/or thermal capabilities of the nanofluids [72-76].

The present experimental study focuses on the influence of the nanoparticle population complexity on the thermal properties of the nanofluid through developing and characterizing nanofluids containing nanoparticles of different particle size-distribution, configurations and shapes. Water based silver-nanofluids (developed via a two-step method in which the nanoparticles were formed through a wet-chemical synthesis route using widely available reagents) are explored as potential candidates for working fluids within a direct absorption solarthermal collection system. The synthesis route allows for the stabilization of the nanofluids through the employment of the surfactant polyvinyl alcohol (PVA) to aid and control the nanoparticle growth. The main advantage of this approach is represented by the fact that the nanofluids manufacturing procedure is simple, relatively low-cost and it can be easily scaled up to be used in real-world solar thermal applications. The optical properties of the colloidal dispersions fabricated were tuned throughout the synthesis stage to deliver a dynamic absorption profile over the $300 \mathrm{~nm}-800 \mathrm{~nm}$ spectral window. The impact of the particle size-distribution, particle morphology, particle concentration and dispersion stability on the photo-thermal conversion efficiency and thermal conductivity of the nanofluids is discussed.

\section{Materials and methods}

\subsection{Ag nanoparticle synthesis}

\subsubsection{Reagents}

Silver nitrate $\left(\mathrm{AgNO}_{3}, 99.99 \%\right)$, sodium borohydride $\left(\mathrm{NaBH}_{4}, 99 \%\right)$, poly-vinyl alcohol (PVA, 87\%-89\% hydrolyzed, typical $\mathrm{M}_{\mathrm{W}}$ $13000-23000 \mathrm{~g} / \mathrm{mol}$ ), tri-sodium citrate (TSC, 99.5\%) and hydrazine $\left(\mathrm{N}_{2} \mathrm{H}_{4}\right.$, hydrate, reagent grade, $\left.50 \%-60 \%\right)$ were all purchased from Sigma Aldrich Co (St. Louis, Missouri, United States) and used without further purification. Ultrapure water $\left(\rho=18.2 \mathrm{M} \Omega \mathrm{cm}^{-1}\right)$ was used throughout the experiment to form the numerous aqueous solutions required for the nanoparticle synthesis route employed.

\subsubsection{Particle nucleation and the formation of $\mathrm{Ag}$ seeds}

In this study, silver nanoparticles were synthesized using a two- 


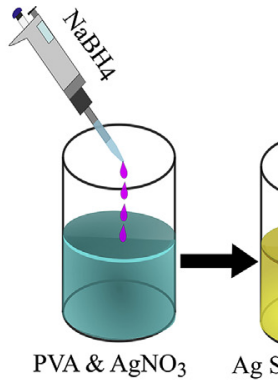

(i)

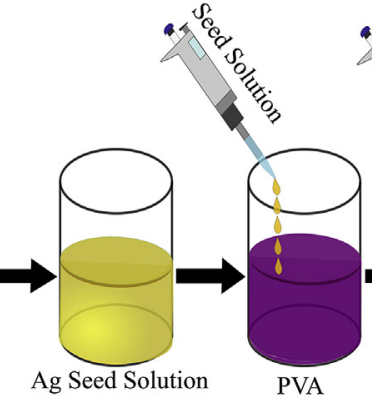

(ii)

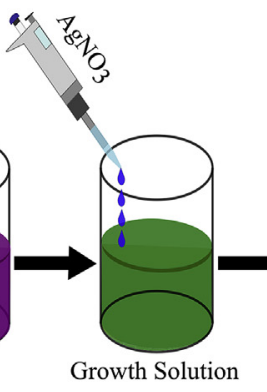

(iv)

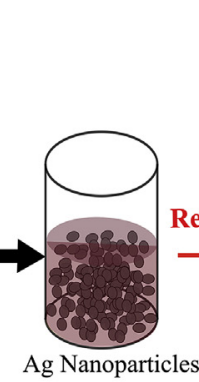

(v)

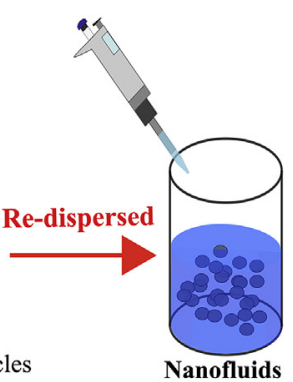

(vi)

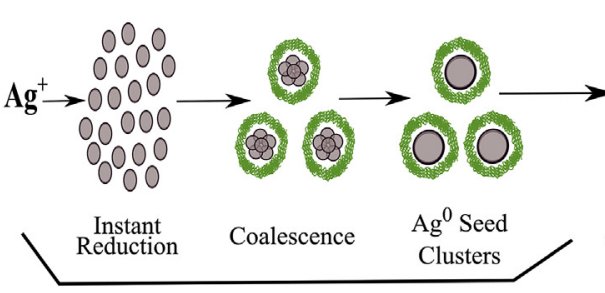

Nucleation

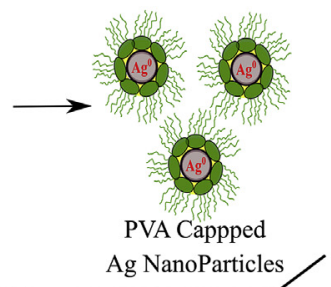

Fig. 1. Schematic representation of the seed-mediated method (i-v) used to synthetize and control the size of silver ( $\mathrm{Ag})$ nanoparticles. Subsequently, the nanoparticles were dispersed in a base fluid to form silver nanofluids (vi). The individual stages of heterogeneous particle growth that is taking place during each stage of the synthesis procedure are also presented.

\begin{tabular}{|c|c|c|c|}
\hline Legend & $\begin{array}{l}\text { Base Fluid (Water) } \\
\text { Silver Seed Solution } \\
\text { Growth Solution (PVA, } \mathrm{N}_{2} \mathrm{H}_{4}, \text { TSC, Seed) }\end{array}$ & $\begin{array}{l}\text { Supernatant } \\
\text { PVA }\end{array}$ & $\begin{array}{l}\text { Seed solution } \\
\mathrm{AgNO}_{3}(0.001 \mathrm{M}) \\
\mathrm{NaBH}_{4}(0.001 \mathrm{M})\end{array}$ \\
\hline
\end{tabular}

stage seed mediated process (Fig. 1) consisting of (I) particle nucleation and (II) particle growth [77-79]. In the first stage silver seeds, prepared by the chemical reduction of silver nitrate $\left(\mathrm{AgNO}_{3}\right)$ with sodium borohydride $\left(\mathrm{NaBH}_{4}\right)$ in the presence of a stabilizing and capping agent poly-vinyl alcohol (PVA), constitutes a 'reference frame' upon which nanoparticles of various sizes and shapes can be formed (Fig. 1, (i) (iii)). In a typical synthesis process $2 \mathrm{ml}$ of chilled $\left(\mathrm{T}<4^{\circ} \mathrm{C}\right) \mathrm{NaBH}_{4}$ $(0.001 \mathrm{M})$ were added dropwise to $2 \mathrm{ml}$ of $\mathrm{AgNO}_{3}(0.001 \mathrm{M})$ and $2 \mathrm{ml}$ of PVA $(1 \% \mathrm{w} / \mathrm{v}$ in $\mathrm{g} / \mathrm{ml})$ while the solution underwent constant agitation via magnetic stirring.

\subsubsection{Controlled Ag Particle growth}

In the second stage, various volumes of $\mathrm{AgNO}_{3}$ were added to a 'growth solution' leading to the formation of colloidal dispersions with various colors tuned through the crystals growth (Fig. 1 (iv) - (v)). In a typical synthesis process, $1 \mathrm{ml}$ of seed solution prepared in stage I was added to $1 \mathrm{ml}$ PVA ( $1 \% \mathrm{w} / \mathrm{v})$, under magnetic stirring. Then, to this resulting dispersion, $3 \mathrm{ml}$ TSC $(0.1 \mathrm{M})$ and $5 \mathrm{ml} \mathrm{N}_{2} \mathrm{H}_{4}(0.1 \mathrm{M})$ were added sequentially forming the 'growth solution'. The nanoparticle dispersions of various colors were produced by adding, under constant agitation, various volumes $(0.4 \mathrm{ml}-20 \mathrm{ml})$ of $\mathrm{AgNO}_{3}(0.001 \mathrm{M})$ to the 'growth solution' in a slow and controlled manner $(\sim 0.03-0.06 \mathrm{ml} / \mathrm{s})$.

\subsection{Nanoparticle characterization}

The formation of Ag nanoparticles was monitored by UV-VIS spectroscopy. The absorbance spectra of a colloidal sample were recorded over the $200 \mathrm{~nm}-800 \mathrm{~nm}$ spectral range using a PerkinElmer Lambda 900 spectrometer (PerkinElmer Inc., Massachusetts, USA) and having ultrapure water as a reference. An integrating sphere configuration was adopted to minimize the scattering losses occurring due to the presence of $\mathrm{Ag}$ nanoparticles within the colloidal dispersions. The dispersions formed were diluted with ultrapure water in a ratio of 1:5 and the measurements were carried out using $10 \mathrm{~mm}$ path length quartz cuvettes. The underlying spectral components, corresponding to the different particle size-distributions present, were determined using spectral deconvolution, Gaussian peaks being considered for curve-fitting in each case. The evolution of the individual spectral components allowed monitoring the growth and the decay of nanoparticles size distributions within the dispersions. The spectral deconvolution consisted of three steps: (1) baseline subtraction, (2) identifying the possible number of peaks by performing the second derivative and (3) curve-fitting of the overall spectrum using Gaussian peaks [80-82]. The fitting criteria adopted in each case were in correspondence with the guidelines available in the references [80-82].

The particle size-distribution, polydispersity index (PDI) and zeta potential of the colloidal dispersions fabricated were measured using a Malvern Nano series ZS Zetasizer (Malvern Instruments Ltd, Malvern, United Kingdom). Hydrodynamic diameter measurements were performed in poly-methyl-methacrylate cuvettes at a temperature of $25^{\circ} \mathrm{C}$ using a He-Ne Laser $(\lambda=633 \mathrm{~nm})$ with a detector angle of $173^{\circ}$. The refractive index and the viscosity values used were that of pure water. Hydrodynamic size and zeta potential are reported as the mean of the three repeated measurements. The error bar values represent the standard deviation of these measurements.

The surface morphology and shape of the Ag nanoparticles were examined using a Hitachi SU-6600 Field Emission Scanning Electron Microscope (FESEM) and/or a Hitachi SU-70 FESEM (Hitachi Ltd, Tokyo, Japan). A typical sample preparation for SEM investigations involved placing a drop of the diluted $\mathrm{Ag}$ nanoparticle solution on a copper grid and allowing $12 \mathrm{~h}$ to dry at room temperature before imaging. The images were analyzed using ImageJ software, employing an automatic threshold routine. The algorithm used to determine the threshold for each case was selected from the methodologies available in Image J. The mean (Sauter) diameter was subsequently calculated using at least 250 particles per sample.

\subsection{Preparation and characterization of silver nanofluids}

Silver nanofluids were prepared by the method schematically summarized in Fig. 1 (i) - (vi). In this method, colloidal silver dispersions containing particles of different sizes and shapes were first prepared using the aforementioned synthesis route (Fig. $1 \mathrm{i}-\mathrm{v}$ ). In each case, a certain volume $(0.05 \mu \mathrm{l}-2.50 \mathrm{ml})$ of the dispersion was re-dispersed into a base fluid - ultrapure water in this work - as presented in Fig. 1 vi. After the addition of the nanoparticles, the resulting nanofluid 
solution was transferred to an ultrasonication bath for 30 min to reduce possible particle agglomeration, which could have occurred during the transfer of the particles into the base fluid [27-28,43]. Characterization at each stage of the nanofluids preparation was carried out to ensure adequate stability of the nanofluids and their photo-thermal property measurements.

UV-VIS spectrophotometry was used to investigate the stability of the nanoparticles within different types of nanofluid i.e. those containing different particle size-distributions and/or a variety of particle shapes. As the plasmon absorption band of a nanoparticle is highly influenced by its size, shape and surrounding environment, the PerkinElmer Lambda 900 spectrophotometer was used to aid in the identification of possible aggregation, upon transferring the particles from the colloidal dispersion into the base fluid $[27,38,43]$.This test was carried out in conjunction with dynamic light scattering and Zetapotential analysis, post particle re-dispersion in the base fluid, to identify subtle changes in the particle size and surface charge distribution. The measurements were performed using a Malvern Nano Series ZS Zetasizer (Malvern Instruments Ltd, Malvern, United Kingdom).

\subsection{Photo-thermal conversion efficiency}

The capability of the nanofluids to capture and convert light across a broad spectral range into usable thermal energy was studied and evaluated using the set-up shown in Fig. 2 (a). A halogen lamp (Griven(C) 1200 MSR), working as a solar simulator, was used to reproduce the natural solar irradiance. This solution was chosen to alleviate the uncertainties which can arise due to the instabilities experienced in the natural lighting conditions. The Griven lamp provided a spectral irradiance closely matching that of the standard AM1.5G reference spectra (Fig. 2 c), commonly used within controlled testing environments to replicate the suns spectral distribution under certain idealized conditions [83]. The Griven lamp delivered a consistent spectral irradiance to within a $4 \%-9 \%$ tolerance range over the entire spectral range of the lamp (Fig. 2 c) with fluctuations in the overall irradiance approaching $4 \%$ over the course of an individual nanofluid characterization cycle (Fig. 2d). The light produced by the lamp was sent to the bottom of a borosilicate glass cell (length $\times$ diameter $=7 \mathrm{~cm} \times 2.3 \mathrm{~cm}$ and a wall thickness of $0.3 \mathrm{~cm}$ ) using a plane mirror oriented at $45^{\circ}$ (Fig. 2 a). The borosilicate glass has a high transparency ( $\sim 95 \%$ ) over the broadband range of frequencies present within the incident spectrum. The glass cell was placed within a polyester insulating foam (used to provide an insulating environment for the cell) with only the bottom surface area of the cell directly exposed to the center of the beam produced by the solar simulator. The possibility of thermal and radiative losses to the surrounding environment were minimized through encasing the entire set-up in an external wooden wall.

For a typical nanofluid characterization measurement, the power of the halogen lamp was adjusted, the irradiance arriving at the nanofluids location being $1220 \pm 50 \mathrm{Wm}^{-2}$. This value was measured at the sample location using a pyranometer (Delta-T BF-3 sunshine sensor) that has a measurement uncertainty of $\pm 5 \mathrm{Wm}^{-2}$. A period of $30 \mathrm{~min}$ was allocated for the lamp to reach stable operating conditions. After this, the glass collector containing the nanofluid under consideration was placed under the illumination of the solar simulator for $90 \mathrm{~min}$. Typically, $25 \mathrm{ml}$ of working fluid was employed within the direct solar absorption collection system, with the $0.05 \%-10 \% \mathrm{v} / \mathrm{v}$ nanofluid loadings prepared by collecting a quantity from the stock nanoparticle solution (step V in Fig. 1) and re-dispersing them into ultrapure water for each type of nanofluid considered.

Four K-type thermocouples (with an uncertainty of $\pm 0.5^{\circ} \mathrm{C}$ ) were positioned at the top and at bottom of the glass collector (as depicted in Fig. 2 b) to monitor the temperature changes within the nanofluid (using the temperature differences between the two thermocouples within the fluid) and with its surrounding environment (using the temperature differences between the thermocouples within and outside the cell) in real time. The temperature probe closest to the inlet was used to resolve changes within the photo-thermal efficiency of the working fluid as a result of the alterations made to the nanoparticles size, shape, and concentration within it. The divergence between the two temperature readings, within the fluid, reveals information on the homogeneity of the heat transfer within the volume of fluid. As the temperature of the working fluid increased during constant irradiation, losses to the surrounding environment became more prevalent. Placing two thermocouples outside the working fluid allowed for these losses to be resolved and quantified. The temperature variations were monitored and recorded every second using a data acquisition system composed of a data logger (Pico TC-08 data logger) interfaced to a computer.

The photo-thermal conversion efficiency (PTE) is commonly defined as the ratio between the energy stored within the nanofluid and the total incident solar irradiation $[35,42]$;

$P T E=\frac{\left(c_{w} m_{w} \Delta T_{w}+c_{n p} m_{n p} \Delta T_{n p}\right)}{I A \Delta t} \approx \frac{c_{w} m_{w}}{I A}\left(\frac{\Delta T_{n f}}{\Delta t}\right)$

where $c_{w}$ and $c_{n p}$ are the specific heat, $m_{w}$ and $m_{n p}$ are the mass, $\Delta T_{w}$ and $\Delta T_{n p}$ are the rise of the temperatures over the measurement period $\Delta t$ of the water (w) and the nanoparticles (np), respectively; $I$ is the irradiation flux and $A$ is the illumination area of the nanofluid. Under low intensity conditions, the temperature difference between the particles and the base fluid is negligible $[35,42,84]$. The low concentrations of particles employed allows the nanoparticles mass contribution to be assumed negligable [42,85-86]. This allows for a general accepted simplification of general equation (1), PTE being now directly proportional to the temperature gradient at a point within the bulk nanofluid $\Delta \mathrm{T}_{n f}$, measured by the thermocouples [35,42,85-86].

The contributions to the PTE arising from latent heat (i.e. due to evaporation) are not considered in the outlined definition of PTE $[42,85-86]$. The relatively low temperatures $\left(<50^{\circ} \mathrm{C}\right)$ involved in this study allow the assumption that these contributions are negligible. The expression employed does not have to consider the losses to the surrounding environment through both radiative and convection processes, as the system was placed in an insulator environment. The enhancement (equation (2)) in the PTE of the nanofluid, as compared to the base fluid, offers a clearer metric of the overall impact of design parameters on the performance of the nanofluid.

Enhancement $=\left(\frac{P T E_{n f}-P T E_{w}}{P T E_{w}}\right) \times 100$

The thermal conductivity of the water $\left(\kappa_{\mathrm{W}}\right)$, the base fluid in this study, and the thermal conductivity of each nanofluid $\left(\kappa_{\mathrm{NF}}\right)$ for various concentrations were measured using the hot-wire method (Fig. S1) as described in detail in the Supplementary Material. The values obtained for the thermal conductivities were used to calculate the ratio $\left(\kappa_{\mathrm{NF}} / \kappa_{\mathrm{W}}\right)$. These results were then compared with the PTE behaviour for the various types of nanofluid (Fig. S2).

\section{Results and discussion}

\subsection{Seed formation}

Seed solutions containing a narrow distribution of particle sizes are essential to the development of controlled nanoparticle growth during the second stage of the synthesis. The deviations in their optical properties can be used as indicatives of the control exerted over the growth kinetics during heterogeneous particle growth [77,79,87-88]. Seed solutions exhibiting a rich golden yellow color (like that presented in Fig. 3 a, inset) represent the ideal case, reflecting the best control granted over the particle formation [77-79]. Darker colors are indicative of increased scattering due to the presence of larger particles 
(a)

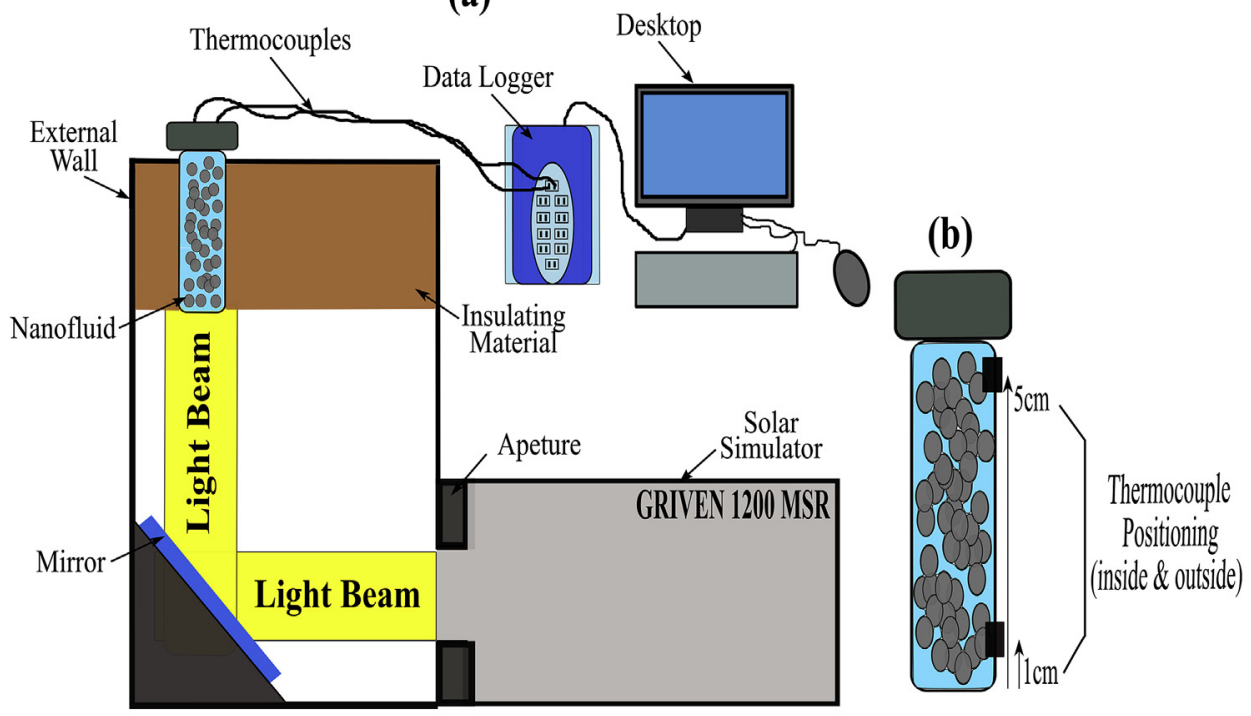

(c)

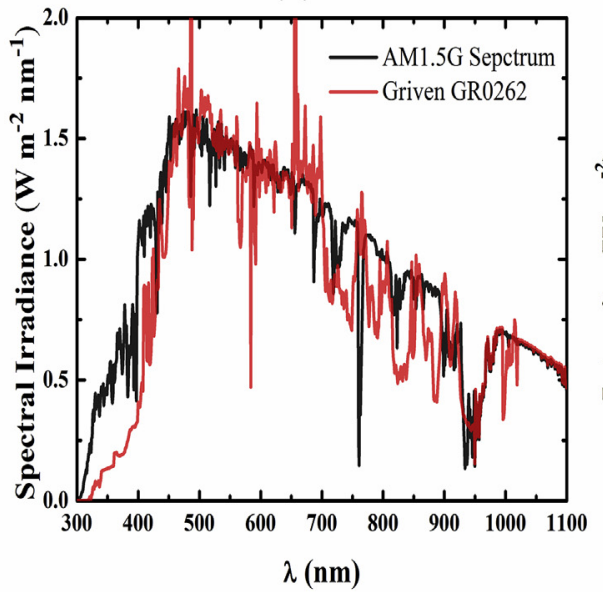

(d)

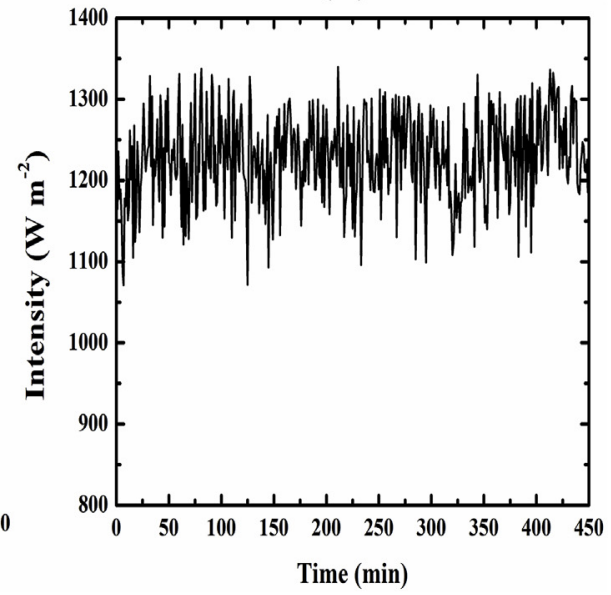

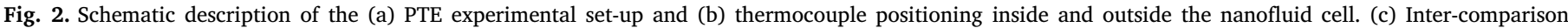

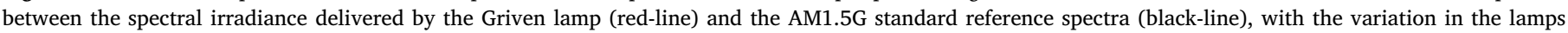

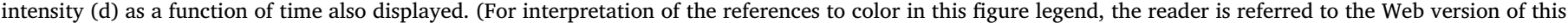
article.)

$[54,77,79,82,104]$. This implies that during the initial stages of particle growth, a larger variation in the size of the 'seed' particles was formed. The origin of this variation is owing to either subtle differences within the growth kinetics of the reaction [54] or, alternatively, to the formation of a larger number of 'seed' particles during nucleation [89]. The larger number of seeds particles formed can allow for a higher predisposition of the seed solutions towards agglomeration and, hence, at a later stage, for a larger variation in the nanoparticle size in the resulting nanofluid.

Typically, a colloidal dispersion containing seed particles $2 \mathrm{~nm}-15 \mathrm{~nm}$ in diameter (Fig. $3 \mathrm{a}$ - inset) has a LSPR absorption band extending from $320 \mathrm{~nm}$ to $450 \mathrm{~nm}$ (Fig. 3 a), with a maximum peak situated at $\sim 400 \pm 5 \mathrm{~nm}$ and a small 'shoulder' peak occurring at $\sim 375 \pm 5 \mathrm{~nm}$. These peaks are characteristic for the formation of spherical Ag nanoparticles [53]. These seeds will be used to tune the growth of the nanoparticles and their optical properties (Fig. $3 \mathrm{~b}-\mathrm{d}$ ). The spherical shape of the seeds is confirmed through SEM (Fig. $3 \mathrm{e}-$ f), where the presence of small particles $(\sim 10 \mathrm{~nm}-20 \mathrm{~nm})$ with approximately spherical shape can be observed. The SEM images (Fig. 3f) also reveal the presence of clusters of seed particles $(\sim 50 \mathrm{~nm}-200 \mathrm{~nm})$. The clusters presence could suggest that possible aggregation might have occurred in the seed solution prior to particle growth. However, in this figure, the cluster formation might also be the result of the deposition technique used for SEM sample preparation. These facts reinforce the need of using the seed solutions immediately after preparation to avoid possible aggregation prior to particle growth.

\subsection{Fine-tuning of colloidal dispersions optical properties}

Colloidal dispersions of different colors (Fig. $3 \mathrm{~b}$ ) were produced by altering the volume of $\mathrm{AgNO}_{3}(0.001 \mathrm{M})$ added to the growth solution during the heterogeneous particle nucleation process. The color of the dispersions shifts from yellow to red and from red to green as the volume of silver nitrate was varied from $0.4 \mathrm{ml}-20 \mathrm{ml}$ (Fig. $3 \mathrm{~b}$ ). Variations within the color of the colloidal dispersions were registered through the modifications in the LSPR absorption band (Fig. $3 \mathrm{c}$ ). These deviations are directly related to the changes in the particle size-distribution $[57,77,79]$. Consequently, it is expected that the shift in peak absorption wavelength $\left(\lambda_{\max }\right)$ of the dispersions to larger wavelengths (Fig. $3 \mathrm{c}$ ) reflects the changes in the particle size-distributions.

As the volume of $\mathrm{AgNO}_{3}$ is increased, the formation of two peaks in the absorption spectra of the dispersions becomes prominent (Fig. $3 \mathrm{c}$ ), indicating the presence of more than one species of nanoparticles. The absorption spectra contain two spectral components (1) a 'static' 

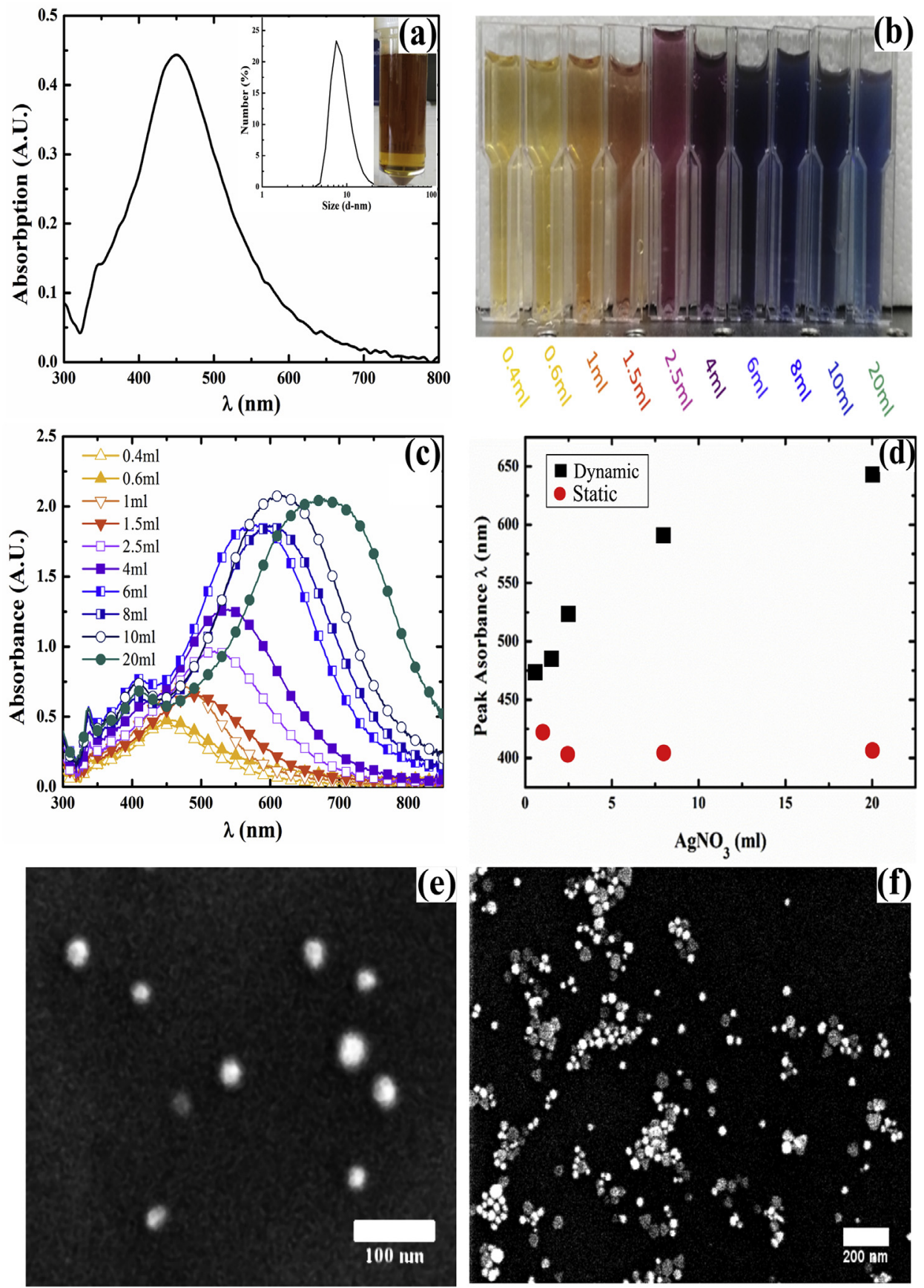

Fig. 3. (a) UV-VIS absorption spectrum of a typical stable colloidal solution containing the AgSeeds. The particle size-distribution and a photograph of the solution are shown as an inset. The rich golden yellow color can be seen. (b) Different colloidal solutions produced when the volume of $\mathrm{AgNO}_{3}(0.001 \mathrm{M})$ is varied during the growth stage of the nanoparticle synthesis and (c) their respective plasmonic absorption bands. As the volume of $\mathrm{AgNO}_{3}$ is varied the formation of two peaks within the LSPR absorption band of the colloidal dispersions becomes discernible. (d) The wavelength $\left(\lambda_{\max }\right)$ of the peak absorption as a function of the volume of $\mathrm{AgNO}_{3}$ leads to two components (1) static - in red and (2) dynamic - black. (e-f) SEM images showing the variation in the size and in the morphology of the particles present within the seed colloidal dispersion prior to the growth stage. (For interpretation of the references to color in this figure legend, the reader is referred to the Web version of this article. component that retains absorption characteristics similar to the seeds used to grow the nanoparticles (Fig. $3 \mathrm{~d}$ - red circles), and (2) a 'dynamic' component which shifts from $450 \mathrm{~nm}$ to $650 \mathrm{~nm}$ as the amount of added $\mathrm{AgNO}_{3}$ varies from $0.4 \mathrm{ml}$ to $20 \mathrm{ml}$ (Fig. $3 \mathrm{~d}$-black squares). Thereby, the particles absorption band can be tuned to cover the entire $350 \mathrm{~nm}-800 \mathrm{~nm}$ spectral window (Fig. $3 \mathrm{c}$ ). This wide absorption band will be very benificial to the solar applications as the amount of solar energy collected will increase. The deconvolution of the spectra (Fig. 4 a $-\mathrm{f}$ ) revealed the presence of more spectral bands contributing to the overall spectrum, with some of the spectra containing as many as five individual contributions (Fig. 4 e). These higher order modes are corresponding to larger particles present within the colloidal dispersions and/or to the existence of anisotropic morphologies [56,90]. The individual spectral contributions arising from higher frequency modes within the colloidal dispersion need to be used to monitor these changes in particle size-distributions and morphologies. The changes seen in
Fig. 4 lead to the conclusion that the nanoparticles present in the dispersions have various size distributions and/or a variety of particle morphologies. The competition between these species within a dispersion can also lead to the observed variation in color (Fig. 3 b). The wide range of particle morphologies is also revealed by the SEM images (Fig. $5 \mathrm{a}-\mathrm{b}$ and Fig. S3), where the presence of cubes, prisms, spheres and other hexagonal and/or non-spherical geometries can be seen.

The origin of the individual absorption properties of each colloidal dispersion lies in the particle-size distribution and morphologies existing within [91-92]. The scattering and the absorption of the light, as well as the characteristics of the locally enhanced electric field (EF) established through LSPR, are controlled by the shape and the size of the nanostructures [90-92]. By controlling the volume of silver nitrate employed during crystal growth, the size of the particle distribution can be tailored from $10 \mathrm{~nm}-50 \mathrm{~nm}$ at low volumes $(0.2 \mathrm{ml}-0.6 \mathrm{ml})$ to $5 \mathrm{~nm}-110 \mathrm{~nm}$ at larger volumes ( $20 \mathrm{ml}$ and above). The particle sizes 
(a)

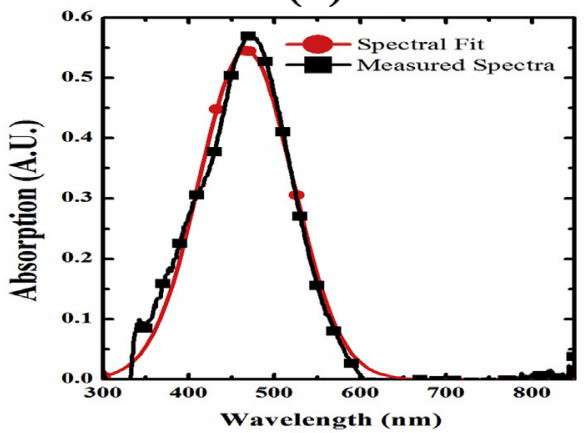

(d)

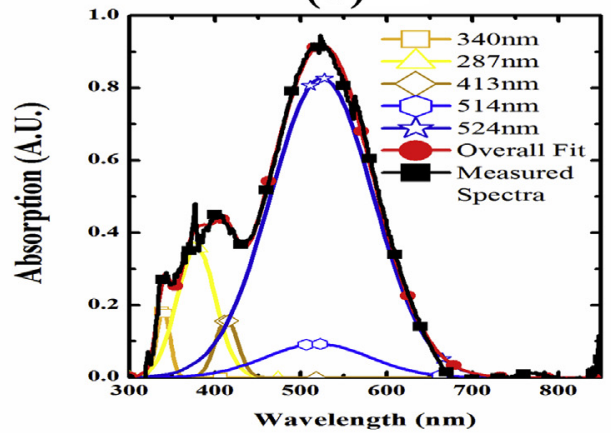

(b)

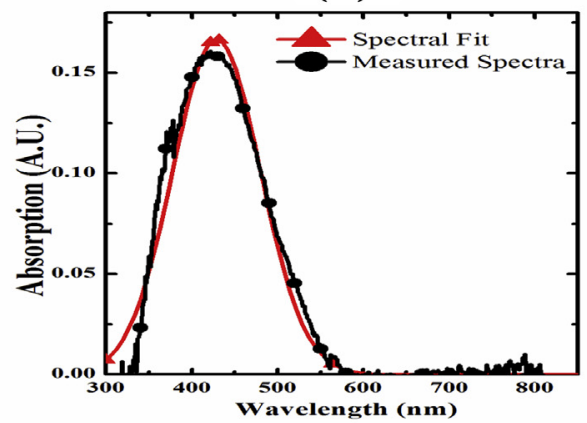

(e)

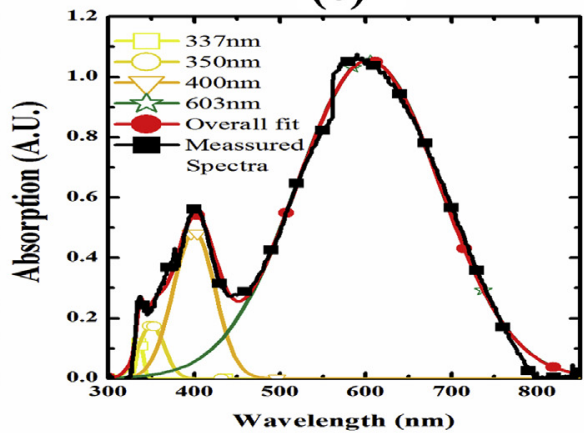

(c)

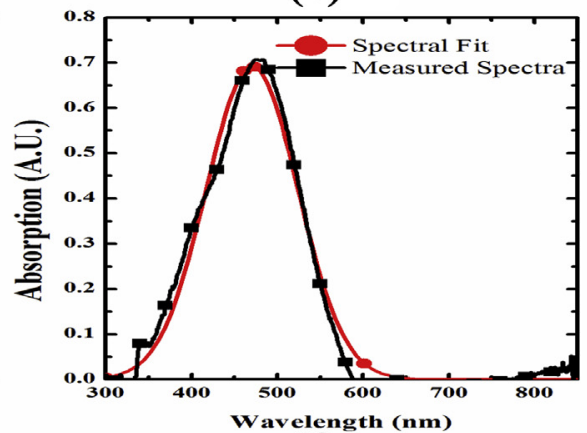

(f)

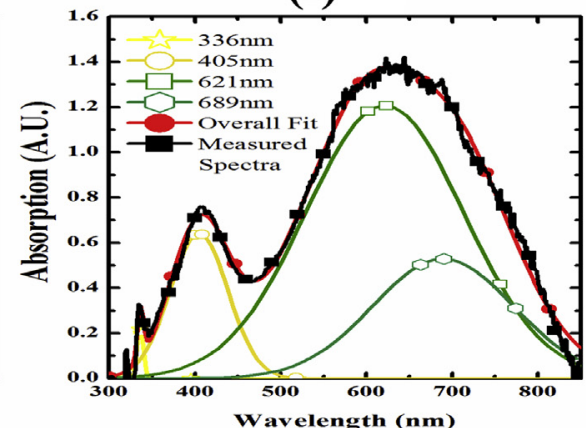

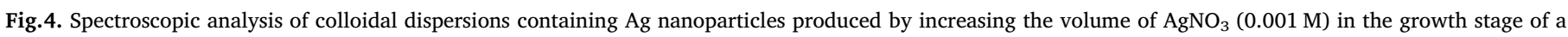

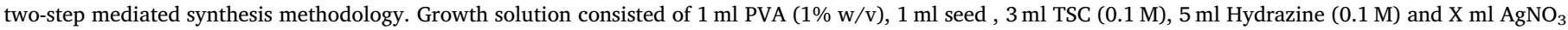

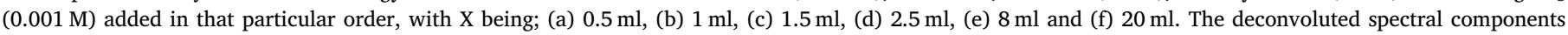
presented indicate the presence of one or more size-distributions of nanoparticles within a dispersion.

reported (Fig. 5 d) have been resolved through SEM size analysis carried out on different 'colored' colloidal dispersions produced using the aforementioned synthesis route. This is correlated with the relationship between the volume of $\mathrm{AgNO}_{3}$ and the PDI (Fig. 5 c) of the colloidal dispersions formed. PDI, a measure of particle distribution broadness, increases rapidly within the $0.4 \mathrm{ml}-2.5 \mathrm{ml}$ added range before taperingoff gradually towards $10 \mathrm{ml}$. At this critical point $(2.5 \mathrm{ml})$, as the particle size-distribution undergoes a transition from an almost purely monomodal to bimodal distribution (Fig. 4), the increasing population of larger particles begins to dominate the scattering characteristics of the signal registered in the photodetector of the DLS device. The formation of the secondary size distribution at this point can be attributed to a gradual decrease in the stability of the dispersion, as the interplay of the competing processes of agglomeration, coalescence and colloid stabilization start to become important.

Within a particle dispersion, the delicate balance between the longrange attractive (typically, London - Van der Waals) forces, which act as the driving force behind the aggregation process, and the repulsive (e.g. steric) interactions will determine the long-term stability of a solution [47]. The aggregation tendency can be retarded by the inclusion of a surfactant or stabilizing agent. The surfactant, in this case PVA, forms a protective layer around the particles allowing for the (steric) stabilization of the dispersions.

The Zeta potential (Fig. 5 c) represents a rapid and efficient method to determine and predict the stability of a particle dispersion [93]. The solutions formed in this study displayed a rapid increase in the stability, with the average zeta potential increasing from $-22 \mathrm{mV}(0.4 \mathrm{ml}$ $\left.\mathrm{AgNO}_{3}\right)$ to $-50 \mathrm{mV}\left(2.5 \mathrm{ml} \mathrm{AgNO}_{3}\right)$. The uncertainty on the Zeta potential is indicative of the variation of particle stability within the collective particle ensemble. As particles can coalescence to form larger structures, their charge distribution will also be altered, affecting the electrostatic interactions within the particle dispersion. This will lead to a distribution of Zeta potential values whose extent will depend upon the internal structure of the fluid.
Therefore, developing an understanding of the degree of control, granted through the many synthesis routes available, over the optical and morphological properties of the nanostructures employed in the development of nanofluids seems to be crucial. Gaining an insight into the impact of specific properties of the structures and their correlation with variations in the photo-thermal performance will allow revisions for design at the synthesis stage. However, such studies are beyond the purpose of the present paper, but we note that these insights should be considered in future studies to maximize the cooperation between the base fluid and nanostructures to enhance the performances and the efficiencies of the photo-thermal energy systems.

\subsection{Nanofluids and their optical properties}

Three different types of nanofluid (Table 1) were designed based on the variation in particles size and morphology of the dispersions previously mentioned. Each type has a distinctive absorption bandwidth and a characteristic particle size distribution, allowing for the effect of each of these parameters on the photo-thermal performance of the fluid to be evaluated. The prepared nanofluids are shown in Fig. $6 \mathrm{a}-\mathrm{c}$ with most of the working fluids appearing transparent, but this effect changes at the higher concentrations $(2 \%-10 \% \mathrm{v} / \mathrm{v})$ where the scattering due to the presence of nanoparticles start to become appreciable. The optical properties of the nanofluids were explored by UV-VIS spectroscopy (Fig. 6 (i) - (iii)). The absorption within the $350 \mathrm{~nm}-800 \mathrm{~nm}$ spectral window increased with increasing the particle concentration. In accordance with the Beer-Lambert law, the relationship between the absorbance and concentration of nanoparticle was found to be linear (see the insets in Fig. 6 (i) - (iii)). An exception from this linear dependence can be noted at very low concentration (less than $1 \% \mathrm{v} / \mathrm{v}$ ).

Type A nanofluids (Fig. 6 (i)) presented a more confined absorption window that is localized within the $350 \mathrm{~nm}-450 \mathrm{~nm}$ region, while Type B (Fig. 6 (ii)) and Type C (Fig. 6 (iii)) nanofluids absorb the light over a 

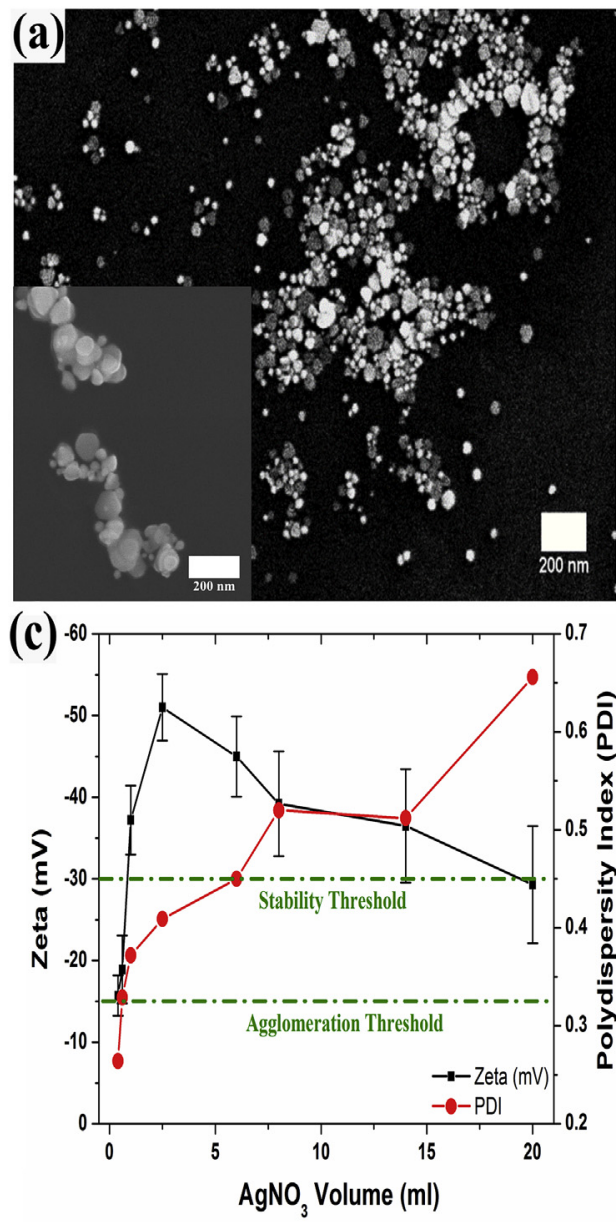

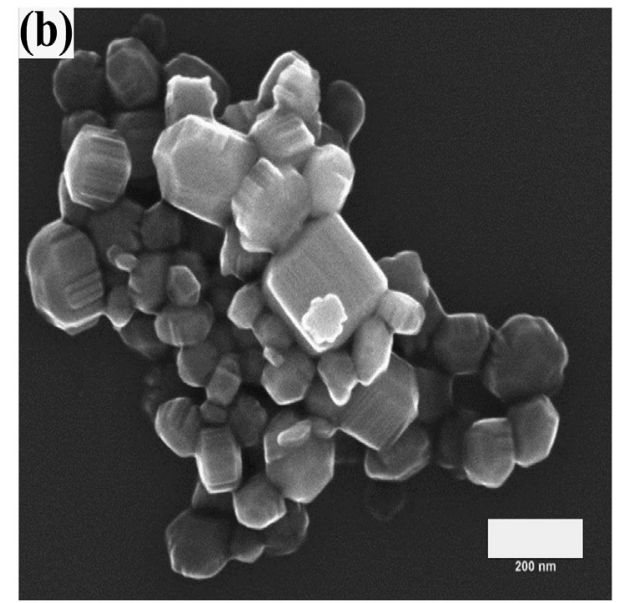

(d)

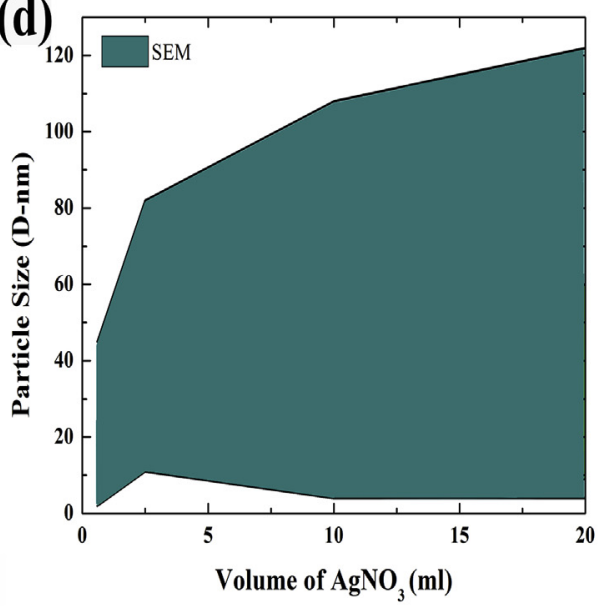

Fig. 5. (a) Overall low-magnification and (b) zoomed SEM images of the Ag nanoparticles in the dispersions. The inset in (a) show higher magnification of the various clusters in the nanofluid solutions. The scale bar in the inset is $200 \mathrm{~nm}$. The wide range of particle morphologies and sizes present within the polydisperse colloidal dispersions formed can be observed. The presence of multiple different size distributions within a given sample can explain the changes in the spectral observations. (c) The deviations in the zeta potential (black squares) and PDI (red circles) of the colloidal dispersions produced as the volume of $\mathrm{AgNO}_{3}(0.001 \mathrm{M})$ is changed in the growth process, and the (d) corresponding change in the particle size throughout this range: as determined through SEM. (For interpretation of the references to color in this figure legend, the reader is referred to the Web version of this article. much larger ( $350 \mathrm{~nm}-800 \mathrm{~nm}$ ) spectral range. Nevertheless, differences in the absorption profiles of these two types of nanofluid can be observed. Type B nanofluids present a peak absorption at $550 \mathrm{~nm}$ owing to the presence of larger particles $\sim 30 \mathrm{~nm}-80 \mathrm{~nm}$ in diameter. Type $\mathrm{C}$ nanofluids have a similar level of absorbance at this wavelength but this type of nanofluid also has an LSPR mode occurring at $420 \mathrm{~nm}$. This mode LSPR seems to correspond to the abundance of particles with sizes (as noticed through SEM and DLS) that are closely matching the size of the seed particles $(2 \mathrm{~nm}-20 \mathrm{~nm})$ used in the nanofluids production. The absorption profile is produced due to the interaction of electromagnetic radiation with the silver nanostructures suspended within water. Therefore, the Ag nanoparticles can provide a more efficient method of capturing and converting the energy within the UV/VIS range i.e. in the region where water is a poor absorber.

\subsection{Photo-thermal performance}

The photo-thermal performance of the nanofluids (Types A - C) were evaluated under the continuous irradiation provided by the solar simulator (Fig. 2). As the working fluid is exposed to the constant irradiation, the temperature of the fluid increases (Fig. 7 a, d and g). Even though water is transparent, most of the near-infrared radiation available is absorbed by the water molecules before being converted into thermal energy [103]. This enables the water to undergo a temperature variation of $12{ }^{\circ} \mathrm{C}$ over $90 \mathrm{~min}$ of exposure time. The silver nanofluids capability to capture and convert visible and ultraviolet light into thermal energy resulted in a much larger temperature variation within the initial few minutes of exposure as compared to pure water (Fig. 7 a, $\mathrm{d}$, and $\mathrm{g}$ ). Thus, during this period the radiation that is transmitted through the glass collector is absorbed and scattered by the nanoparticles. The presence of nanoparticles decreases the optical path within the working fluid leading to the partial transmission of spectral radiation within the working volume [47-48,94]. The particles are forming a 'collecting' area within which the interactions between the chemical species present lead to a rapid transfer of heat to the residual working volume. The temperature of the working fluid reaches the value of $42^{\circ} \mathrm{C}$. Further increases in temperature start to become less pronounced, as reflected by the PTE values at the later stages of the experiment (Fig. 7 b, c and h). This is owing to the gradual increase in the temperature difference between the working fluid and the surrounding environment, as the working fluid is under the constant electromagnetic flux.

Table 1

The different types of nanofluid designed through varying the volume of silver nitrate $(0.001 \mathrm{M})$ added during the growth stage of the synthesis employed, and their respective typical particle sizes, absorption range \& particle distribution type.

\begin{tabular}{|c|c|c|c|c|}
\hline & Volume of $\mathrm{AgNO}_{3}(0.001 \mathrm{M})$ required for particle growth $(\mathrm{ml})$ & Particle Diameter (nm) & Particle distribution Type & Absorption Range (nm) \\
\hline Type A & 0.4 & $10-50$ & Single mode & $300-500$ \\
\hline Type B & 4 & $10-85$ & Bi-modal & $300-700$ \\
\hline Type C & 20 & $5-120$ & Bi-modal & $300-750$ \\
\hline
\end{tabular}



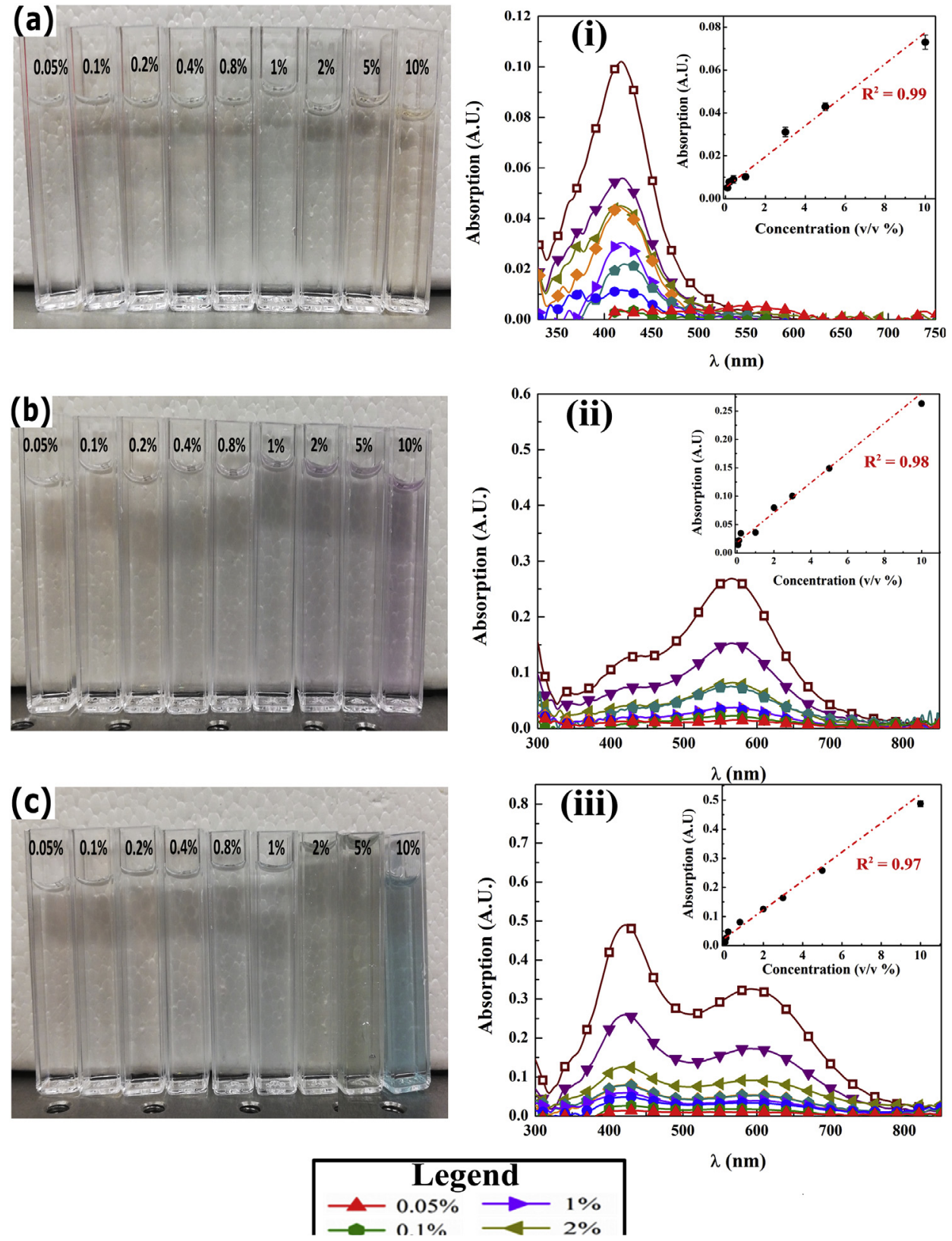

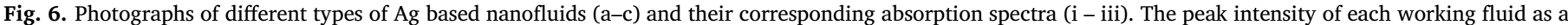

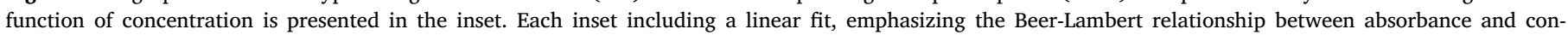
centration for each nanofluid considered.

Enhancement gained through the inclusion of PVA stabilized silver nanoparticles within the base fluid did not follow the typical relationships commonly reported in metal-based nanofluids [26-28,43]. Thus, typically, the presence of smaller particle size and an increasing particle concentration are reported to lead to significant enhancements in the photo-thermal performance of the working fluid [30]. Nonetheless, in the system studied, these trends were not observed. Moreover, for some of the nanofluids in this study, a rather non-linear variation of the PTE enhancement with exposure time was observed (Fig. 7 c, f and i), with the rate of increase or decrease in photo-thermal performance varying from sample to sample. However, this might be explained by the fact that there is a capability of the particle size to overwrite the particleconcentration effect [26].

The type A fluids displayed the lowest increase in the PTE enhancement value among the three nanofluids, but, even in these conditions, it still exhibited a PTE larger by $10 \%-19 \%$ than the PTE of the base fluid (Fig. 7 c). The presence of a narrow absorption bandwidth of the particles (Fig. 6 i) that captures less solar irradiance can explain their lower performance when compared with the other two types. The smaller size particles present within the fluid $(\sim 10 \mathrm{~nm}-50 \mathrm{~nm})$ should have led to better heat transfer kinetics for this type of nanofluid [30,95]. However, the low $(-20 \mathrm{mV})$ zeta potential of colloidal dispersions produced using such small volumes of $\mathrm{AgNO}_{3}$ (Fig. $5 \mathrm{c}$ ) could lead to the onset of thermally aided aggregation during the exposure and this aggregation can hamper the thermal properties. The substantial increase in the fluid temperature, especially for certain concentrations $(0.2 \%, 0.4 \%$ and $1 \% \mathrm{v} / \mathrm{v})$, within the first $1000 \mathrm{~s}$ of exposure can suggest that these nanofluids could be tailored towards applications where their short-time enhanced performances (i.e. when exposed to such short bursts of high intensity spectral irradiance) are more suitable. In some instances, e.g. for certain nanoparticle concentrations, the photo-thermal performance of the base fluid was 

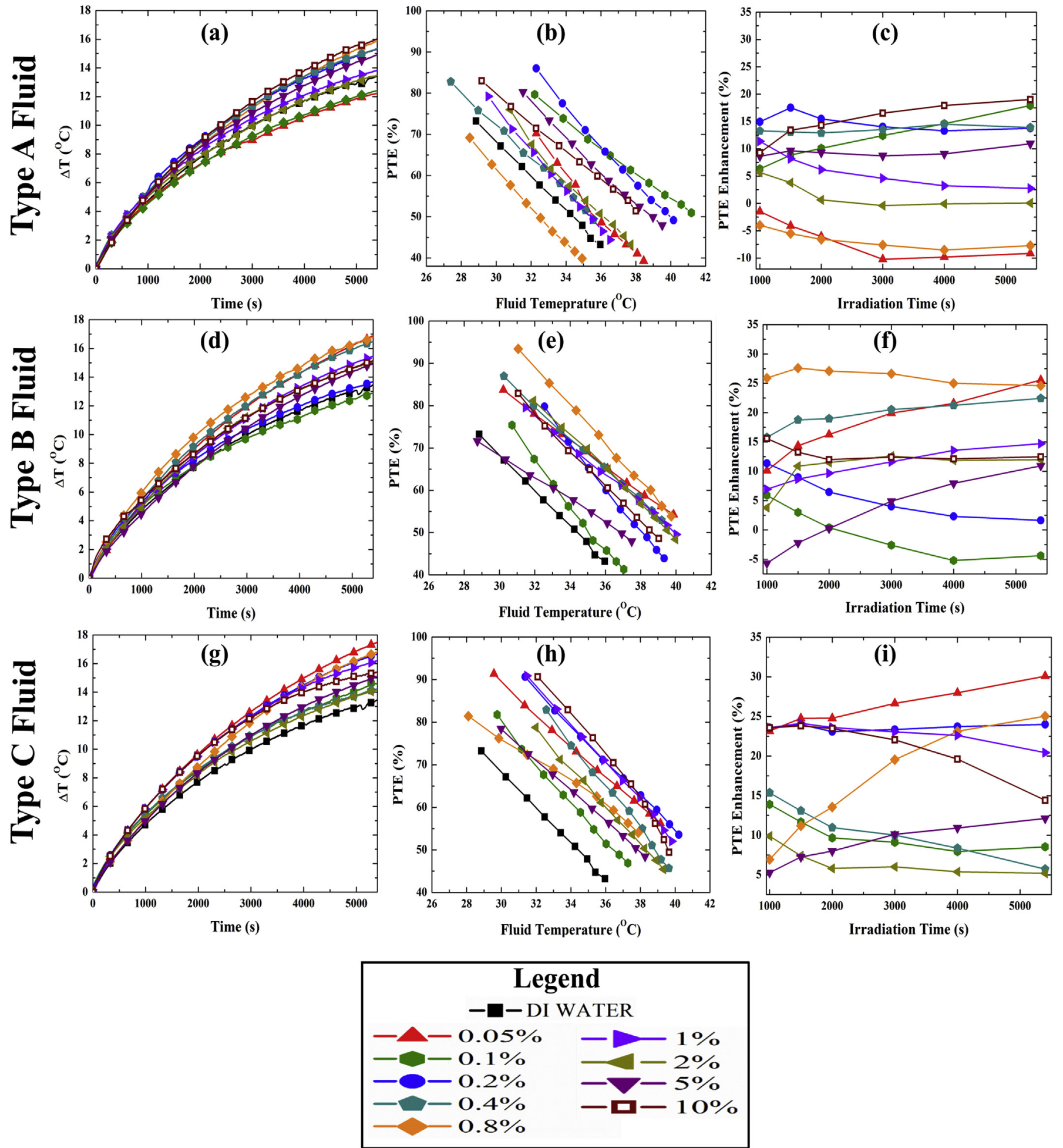

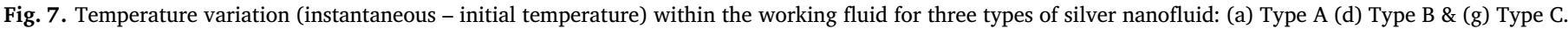

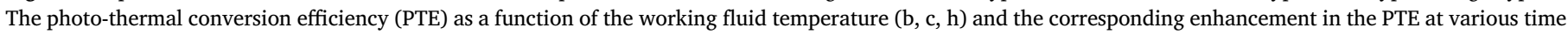
during the 90-min exposure period (c, f, i).

unfavorably affected by the inclusion of the nanoparticles (Figs. $7 \mathrm{c}-$ $0.5 \% \mathrm{v} / \mathrm{v}$ and $0.8 \% \mathrm{v} / \mathrm{v}$ ) as this inclusion lead to a decrease of the fluids performance by as much as $10 \%$. Similar effects have been reported, typically, when employing surfactants or stabilizing agents. These molecules can effectively reduce the extensive hydrogen-bonding network found in water [53], this network being considered responsible for water increasing thermal conductivity with temperature [53].
Therefore, nanofluids containing a much larger concentration of type A particles $(\sim 10 \% \mathrm{v} / \mathrm{v})$ represent a better candidate for solar thermal applications, which typically require lengthy exposure times and fluid lifetime cycles [24,96-97].

The type B nanofluids exhibited, depending upon the particle concentration, PTE values with $11 \%-26 \%$ larger than the PTE of the base fluid as reflected by the PTE enhancement (Fig. $7 \mathrm{f}$ ). However, the rate 
of variation in the PTE with exposure time differ across the nanoparticle concentration range investigated. Thus, some nanofluids are displaying a more steeply decline in their photo-thermal performance than others. A similar behavior as for type A nanofluids was observed, with some of the nanofluids $(0.4 \%$ and $0.8 \%)$ initially performing well within the first $2000 \mathrm{~s}$ of exposure. During the later stages of the exposure time, and as the temperature of the fluid increases (Fig. 7 e), their photothermal performance was overcome by nanofluids containing much smaller concentrations of particles $(0.05 \% \mathrm{v} / \mathrm{v})$.

The difference between the two types of fluid can be lying in the prevalence of the high concentrations of type A nanoparticles in providing the largest enhancement reported, while the lowest concentration of Type B nanoparticles investigated provided the best compromise between thermal performance and photo-stability. Another noticeable difference between the two types of nanofluid is the emergence of an enhancement in the photo-thermal efficiency of type B fluids when compared with type A. This is valid irrespective of the concentration of particles present, exception being the $0.1 \% \mathrm{v} / \mathrm{v}$ (Fig. 7 e) sample. The improvement in performance is likely to be due to the interaction of the type B nanoparticles with a much larger band of frequencies. This is due to the presence of a bi-modal size-distribution (Fig. 4) as well as to the different particle morphologies present within each size distribution (Fig. $5 \mathrm{a}$ and b).

The best performances were obtained with the type C nanofluids, that showed an increase in PTE of up to $32 \%$ when compared with the base fluid (see PTE enhancement in Fig. 7 i). All the nanofluids within this category exhibited an enhancement in the performance when compared with the base fluid irrespective of the concentration of particles present. The large ensemble of particle sizes present within these fluids (Figs. 4, 8 and 9), enables a much stronger coupling between the electric fields within the incident irradiance and the oscillating waves of electrons established on the dispersed structures surface (Fig. 6 (iii)). Similarly, with the type B nanofluids the dominance of low concentration $(0.05 \% \mathrm{v} / \mathrm{v})$ working fluids in providing the best enhancement in the photo-thermal performance was once again observed.

The different modes of particle sizes present within the collective network of particles, are possibly responsible for the dominating characteristics displayed by type $C$ nanofluids [82]. The larger particles in the collective ensemble allow the higher order LSPR modes to be involved in the particle-particle interactions within the nanofluid $[47,66]$. Thus, these can generate local enhancements in electromagnetic fields to values that are many orders of magnitude above those achievable through monomodal particle size-distributions [66-68]. The capability of different particle morphologies to facilitate in the formation of a more tightly or loosely packed particle network chain, during the particle agglomeration process, must be also considered. As more particles, which can be effectively packed within the extended particle networks, are formed the higher the thermal conductivity a nanofluid can exhibit $[66-68,76,98]$. In fact, the thermal conductivity measurements performed for these nanofluids show that the thermal conductivity ratio $\left(\kappa_{\mathrm{W}} / \kappa_{\mathrm{NF}}\right)$ has a similar non-linear behaviour as the PTE as the concentration increases (see Fig. S2).

The interactions between neighboring particles can destabilize the nanofluid via aggregation as the attractive forces between nanoparticles lead to the formation of clusters, islands and even fractal networks in an attempt to minimize the free energy within the nanofluid [99-100]. However, while establishing the role of these interactions and explaining the molecular mechanism behind these effects should be investigated, such investigations are beyond the purpose of the present study. The heat transfer mechanics of a nanofluid can be affected by a number of interactions possible within it: (1) the Brownian motion of particles within the liquid, resulting in the formation of a 'convection like' effect. In this case the particles can collide during their random path within the fluid influencing the thermal properties; (2) the interaction of particles with molecules of the base fluid; (3) layering of the liquid at the liquid/nanoparticle interface altering the thermal boundary resistance between the particles and the base fluid; (4) the highly localized near field radiation created through the LSPR phenomena and (5) the formation of loose particle chains or particle networks within the fluid as aggregation begins to occur [29-30,59]. Theoretical studies aimed at removing the veil on the impact of nanoparticle properties (composition, shape and size), interaction pathways and environmental factors (temperature and $\mathrm{pH}$ ) on the heat transfer mechanisms within nanofluids suggest that the presence of aggregates can be primarily responsible for some of the high thermal conductivities of nanofluids [4-6,47,64,89,94,101,105].

Consequently, a thorough characterization of the internal structure of a nanofluid is required both prior to sample testing as well as post exposure to ascertain any changes which may have occurred within the particle size-distribution and/or morphology during the heating of the fluid. The overall particle size distribution resolved through dynamic light scattering can be deconvoluted. This technique allows for the identification of the individual size-distributions that are otherwise hidden underneath the typical bin sizes imposed through most commercial devices. Thus, this allows for the multiple size-distributions, present within the collective particle ensemble, to be resolved. A snapshot in the post-thermal exposure of the particle size-distribution present within each of the nanofluids indicates the emergence of the presence of additional size-distributions and an increase in the maximum particle-size with increasing particle concentration (Fig. 8).

The more particles are present the more by-products of the aggregation process are observed within the nanofluids. This is indicated by the emergence of more modes (blue star in Fig. 8) as well as a larger range of particle sizes post exposure to the solar simulator (Fig. 8). This confirms that the individual spectral contributions resolved within the colloids plasmon absorption band (Fig. 4) are corresponding to the presence of multiple particle size distributions within it. The best performing nanofluids, i.e. type C nanofluids, display an array of sizedistributions, whose peak size lies in close proximity to each other (Fig. 8 e). The other two types of nanofluid, A and B, contain mostly non-overlapping size distributions (see the presence of the error bars overlap in Fig. 8). This can limit the interactions between similar sized particles within the numerous distributions present within nanofluids and, consequently, their photo-thermal properties.

The origin of the effectiveness of the heat transfer process, across all three nanofluids, seems to lie in the upper limit imposed on the maximum size of the particles, which are able to produce the best enhancement in the photo-thermal performance of the base fluid [102]. The best performing concentrations ( $5 \% \mathrm{v} / \mathrm{v}$ type A, $0.05 \% \mathrm{v} / \mathrm{v}$ type B and $0.05 \% \mathrm{v} / \mathrm{v}$ type C) contained particles no more than $150 \mathrm{~nm}$ in diameter (Figs. 8 and 9). Once particles, whose size exceeds this threshold, become involved in the heat transfer process their physical properties appear to dominate the thermo-physical characteristics of the nanofluid, resulting in a decrease in the nanofluids photothermal performance.

Examples of the individual particle size distributions present in solutions whose concentrations resulted in 'poor' and 'good' photothermal performance is provided in Fig. 9. This confirms that the presence of particles with sizes no greater than $150 \mathrm{~nm}$ in the best performing nanofluids. The highest performance from the nanofluids is obtained when a degree of overlap exists between the particle sizedistributions (Fig. 8 red triangles/green circles). The variation in the particle size-distribution seen in the best performing nanofluids can allow for a better packing order of the nanoparticles, which, along with the particle size, has a significant influence on the enhancement of the thermal conductivity [94]. The deterioration in the performance of the remaining fluids is likely to be the result of the emergence of additional modes (Fig. 8 - shown in blue stars and in Fig. 9) corresponding to particle sizes above $150 \mathrm{~nm}$ in diameter. Thus, the delicate balance of the competitive processes between the multiple modes already present within the nanofluid, is deteriorated as the aggregation process accelerates. However, further studies should be performed in order to 

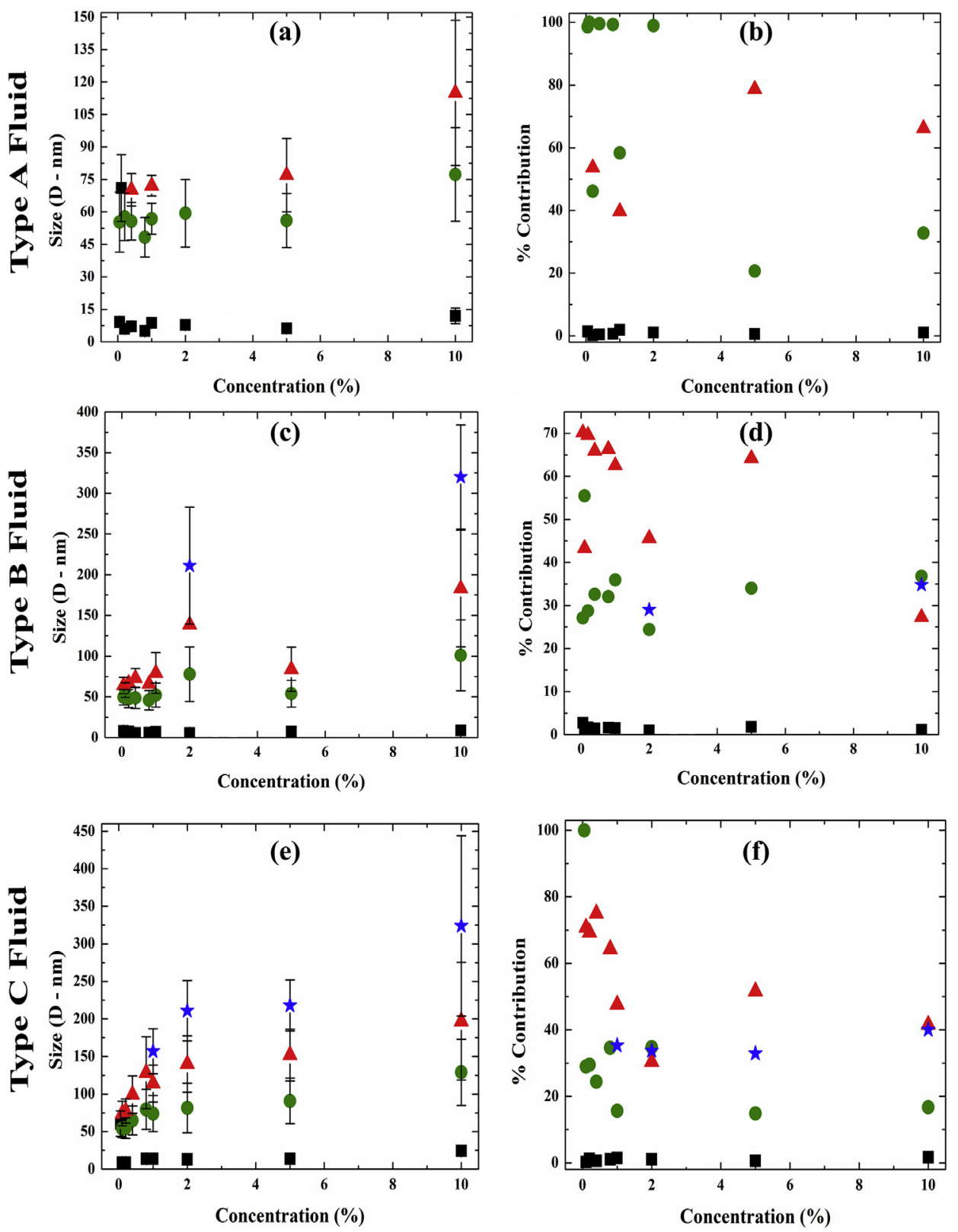

Fig. 8. The post-exposure particle size-distributions (black squares, red triangles, green circles and blue stars) present within the three different types of silver nanofluid (a) type A (c) type B and (e) type $\mathrm{C}$ as a function of the particle concentration within the fluid. The error bars represent the full width half maximum of each individual size distribution within the collective particle ensemble. The error bars are also an indication of the presence of overlapping between the various particle size-distributions. The percentage (\%) contribution from each individual component to the overall size-distribution for each type of fluid (b) type A (d) type B and (f) type $\mathrm{C}$ is also presented. (For interpretation of the references to color in this figure legend, the reader is referred to the Web version of this article. understand the underlying molecular mechanism that stays behind the changes in the photo-thermal properties of these nanofluids. Such studies should involve both experimental and theoretical investigations and should contain a well-defined mixture ratios of nanoparticles with various known sizes, morphology and concentration. Moreover, to determine the feasibility of these nanofluids for concentrating solar plant (CSP) systems, the photo-thermal conversion efficiency and stability after two or more exposure cycles to the solar spectrum should be investigated [4-6,31-32].

\section{Conclusion}

Nanofluids can become a suitable and low-cost alternative to improve the efficiencies of the heat transfer fluid employed within solarthermal and photovoltaic-thermal collection systems. Here, nanofluids containing multimodal silver nanostructures of a rich morphology were synthesized and their thermo-optical properties were studied. The synthesis method presented allows the bandwidth of energy captured by the structures to be tuned, through controlling the concentration of silver nitrite used during the heterogeneous growth of the nanoparticles. This synthesis procedure is simple, relatively low-cost and, once the mechanisms are properly understood, it can be easily scaled up from the lab bench experiment to be used in real-world solar thermal applications. Different variations of silver nanofluids have been designed. Thus, different types of particle size-distribution have been incorporated in the base fluid and their impact on the thermo-optical properties of the resulting nanofluid was explored. Low concentrations $(0.05 \%-0.1 \% \mathrm{v} / \mathrm{v})$ provided the best improvement in the photo-thermal conversion efficiency, with 5\%-32\% enhancements in the PTE being achieved. The variations emerging in the photo-thermal conversion efficiency, can be correlated to changes in the individual populations of the numerous size-distributions contained within the internal structure of the nanofluid. The existence of an upper threshold in the particle size was observed to limit the enhancement in thermal properties, a strong degree of correlation between the individual size-distributions and increased performance being noted. The different particle size modes present, show that using one (and/or narrow) particle size-distribution does not represent the best choice in controlling and optimizing the 


\section{Good Performance}
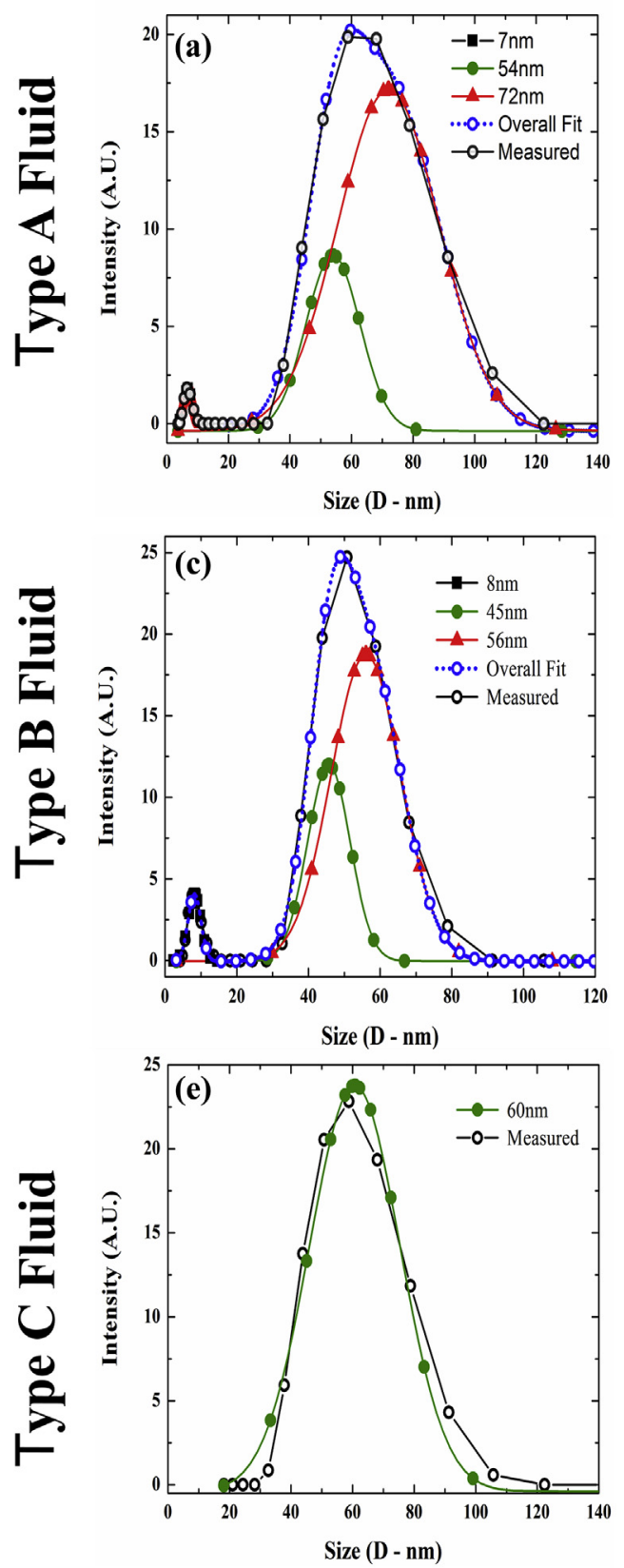

Poor Performance
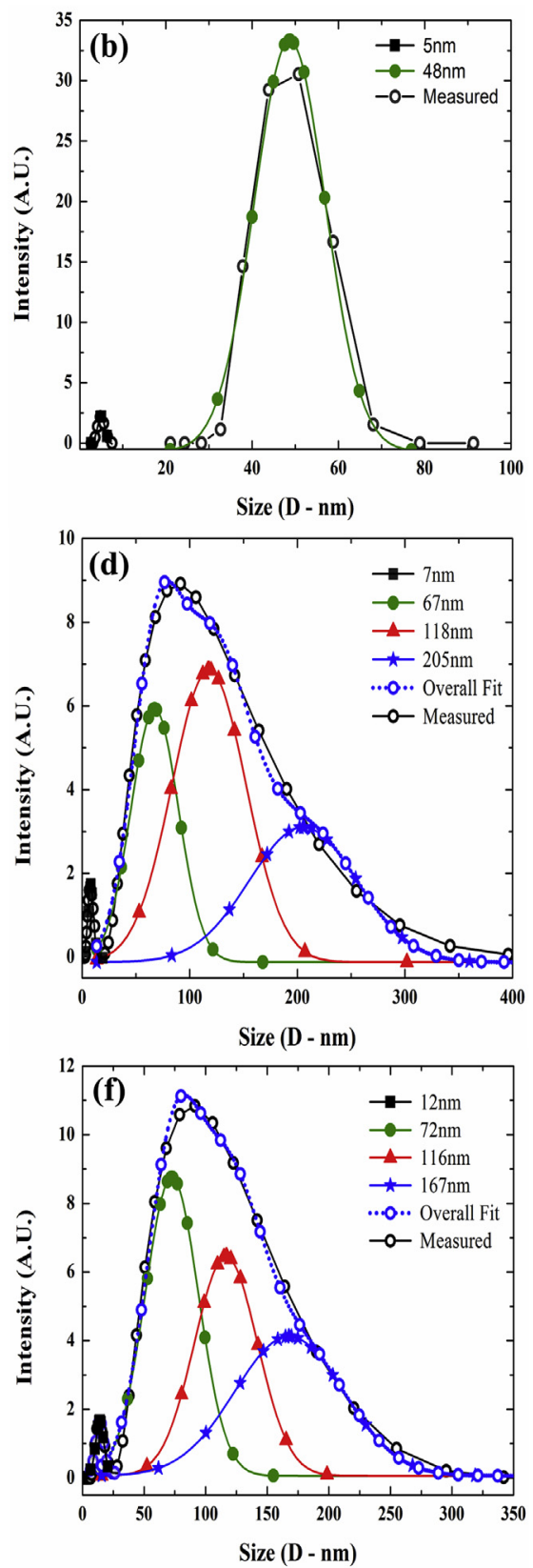

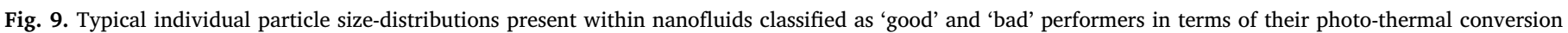
efficiency: (a) $5 \%$ type A (b) $0.8 \%$ type A (c) $0.05 \%$ type B (d) $2 \%$ type B (e) $0.05 \%$ (f) $2 \%$ type C.

heat transfer properties of a nanofluid. Therefore, more work is required to understand the process through which a wide distribution of particle sizes enhances the thermal properties, as this could allow a faster implementation of the nanofluids into more solar applications in the future.

\section{Acknowledgements}

The authors would like to acknowledge funding provided through the TUDublin Fiosraigh scholarship program. The authors also acknowledge the FOCAS Institute for use of equipment and facilities at the Technological University Dublin.

\section{Appendix A. Supplementary data}

Supplementary data to this article can be found online at https:// doi.org/10.1016/j.solmat.2019.110085.

\section{References}

[1] Energy Information Administration (EIA) Agency, Annual Energy Outlook 2017: with Projections to 2050, United Sates Of America, 2017.

[2] M.Z. Jacobson, M.A. Delucchi, Providing all global energy with wind, water, and solar power, Part I: technologies, energy resources, quantities and areas of infrastructure, and materials, Energy Policy 39 (3) (2011) 1154-1169 https://doi.org/ 10.1016/j.enpol.2010.11.040.

[3] World Economic Forum, The Global Risks Report, twelfth ed., World Economic Forum, Geneva, Switzerland, 2017.

[4] E.I. Martín, A. Sánchez-Coronilla, J. Navas, R. Gómez-Villarejo, P. MartínezMerino, R. Alcántara, C. Fernández-Lorenzo, Revealing at the molecular level the role of the surfactant in the enhancement of the thermal properties of the gold 
nanofluid system used for concentrating solar power, Phys. Chem. Chem. Phys. 20 (2018) 2421-2430, https://doi.org/10.1039/C7CP05384C.

[5] R. Gómez-Villarejo, J. Navas, E.I. Martín, A. Sánchez-Coronilla, T. Aguilar, J.J. Gallardo, D. los Santos, R. Alcántara, C. Fernández-Lorenzo, J. Martín-Calleja, Preparation of Au nanoparticles in a non-polar medium: obtaining high-efficiency nanofluids for concentrating solar power. An experimental and theoretical perspective, J. Mater. Chem. A. 5 (2017) 12483-12497, https://doi.org/10.1039/ C7TA00986K.

[6] R. Gómez Villarejo, E.I. Martín, A. Sánchez-Coronilla, T. Aguilar, J. Gallardo, P. Martínez-Merino, I. Carrillo-Berdugo, R. Alcántara, C. Fernández-Lorenzo, J. Navas, Towards the improvement of the global efficiency of concentrating solar power plants by using Pt-based nanofluids: the internal molecular structure effect, Appl. Energy 228 (2018) 2262-2274, https://doi.org/10.1016/j.apenergy.2018. 07.062 .

[7] A. Kazemi-Beydokhti, S.Z. Heris, Thermal optimization of combined heat and power (CHP) systems using nanofluids, Energy 44 (2012) 241-247 https://doi. org/10.1016/j.energy.2012.06.033.

[8] M. Sardarabadi, M. Passandideh-Fard, S.Z. Heris, Experimental investigation of the effects of silica/water nanofluid on PV/T (photovoltaic thermal units), Energy 66 (2014) 264-272 https://doi.org/10.1016/j.energy.2014.01.102.

[9] S. Musi, N. Filipovi-Vincekovi, L. Sekovani, Precipitation of amorphous SiO2 particles and their properties, Braz. J. Chem. Eng. 28 (2011) 89-94.

[10] H. Salehi, S. Zeinali Heris, S.H. Noie, Water-silver nanofluid application in a TPCT under an external magnetic field, Heat Transf. Res. 41 (2012) 289-301, https:// doi.org/10.1002/htj.21006.

[11] A. Amiri, M. Shanbedi, H. Eshghi, S.Z. Heris, M. Baniadam, Highly dispersed multiwalled carbon nanotubes decorated with Ag nanoparticles in water and experimental investigation of the thermophysical properties, J. Phys. Chem. C 116 (2012) 3369-3375, https://doi.org/10.1021/jp210484a.

[12] O. Mahian, A. Kianifar, S.Z. Heris, D. Wen, A.Z. Sahin, S. Wongwises, Nanofluids effects on the evaporation rate in a solar still equipped with a heat exchanger, Nano Energy 36 (2017) 134-155 https://doi.org/10.1016/j.nanoen.2017.04.025.

[13] H. Chaji, Y. Ajabshirchi, E. Esmaeilzadeh, S.Z. Heris, M. Hedayatizadeh, M. Kahani, Experimental study on thermal efficiency of flat plate solar collector using TiO2/water nanofluid, Mod. Appl. Sci. 7 (2013) 60-69.

[14] M. Malinowski, J.I. Leon, H. Abu-Rub, Solar photovoltaic and thermal energy systems: current technology and future trends, Proc. IEEE 105 (11) (2017) 2132-2146 https://doi.org/10.1109/JPROC.2017.2690343.

[15] O. Mahian, A. Kianifar, S.Z. Heris, S. Wongwises, First and second laws analysis of a minichannel-based solar collector using boehmite alumina nanofluids: effects of nanoparticle shape and tube materials, Int. J. Heat Mass Transf. 78 (2014) 1166-1176 https://doi.org/10.1016/j.ijheatmasstransfer.2014.07.009.

[16] S.Z. Heris, A. Kazemi-Beydokhti, S.H. Noie, S. Rezvan, Numerical study on convective heat transfer of $\mathrm{AL2O}$ /water, $\mathrm{CuO}$ /water and $\mathrm{Cu}$ /water nanofluids through square cross-section duct in laminar flow, Eng. Appl. Comput. Fluid Mech. 6 (2012) 1-14, https://doi.org/10.1080/19942060.2012.11015398.

[17] A. Kianifar, S.Z. Heris, O. Mahian, Exergy and economic analysis of a pyramidshaped solar water purification system: active and passive cases, Energy 38 (2012) 31-36 https://doi.org/10.1016/j.energy.2011.12.046.

[18] S. Zeinali Heris, S.H. Noie, E. Talaii, J. Sargolzaei, Numerical investigation of $\mathrm{Al} 2 \mathrm{O} 3$ /water nanofluid laminar convective heat transfer through triangular ducts, Nanoscale Res. Lett. 6 (2011) 179, https://doi.org/10.1186/1556-276X-6-179.

[19] REN21, Renewables 2018 Global Status Report, REN21 Secretaria, Paris, 2018.

[20] M.T. Islam, N. Huda, A.B. Abdullah, R. Saidur, A comprehensive review of state-ofthe-art concentrating solar power (CSP) technologies: current status and research trends, Renew. Sustain. Energy Rev. 91 (2018) 987-1018 https://doi.org/10. 1016/j.rser.2018.04.097.

[21] O. Behar, Solar thermal power plants - a review of configurations and performance comparison, Renew. Sustain. Energy Rev. 92 (2018) 608-627 https://doi. org/10.1016/j.rser.2018.04.102.

[22] S.S. Joshi, A.S. Dhoble, Photovoltaic -Thermal systems (PVT): technology review and future trends, Renew. Sustain. Energy Rev. 92 (2018) 848-882 https://doi. org/10.1016/j.rser.2018.04.067.

[23] M. Charjouei Moghadam, M. Edalatpour, J.P. Solano, Numerical study on conjugated laminar mixed convection of alumina/water nanofluid flow, heat transfer, and entropy generation within a tube-on-sheet Flat Plate solar collector, J. Sol. Energy Eng. 139 (4) (2017), https://doi.org/10.1115/1.4036854.

[24] G. Colangelo, E. Favale, P. Miglietta, A. de Risi, Innovation in flat solar thermal collectors: a review of the last ten years experimental results, Renew. Sustain. Energy Rev. 57 (2016) 1141-1159 https://doi.org/10.1016/j.rser.2015.12.142.

[25] C.G. Granqvist, G.A. Niklasson, Solar energy materials for thermal applications: a primer, Sol. Energy Mater. Sol. Cells 180 (2018) 213-226 https://doi.org/10. 1016/j.solmat.2018.02.004.

[26] S.K. Das, S.U.S. Choi, H.E. Patel, Heat transfer in nanofluids-a review, Heat Transf. Eng. 27 (10) (2006) 3-19 https://doi.org/10.1080/01457630600904593.

[27] D. Dey, P. Kumar, S. Samantaray, A review of nanofluid preparation, stability, and thermo-physical properties, Heat Transf. Asian Res. 46 (8) (2017) 1413-1442 https://doi.org/10.1002/htj.21282.

[28] M. Jama, T. Singh, S.M. Gamaleldin, M. Koc, A. Samara, R.J. Isaifan, M.A. Atieh, Critical review on nanofluids: preparation, characterization, and applications, J. Nanomater. 2016 (2016) 1-22 http://doi.org/10.1155/2016/6717624.

[29] J.J. Wang, R.T. Zheng, J.W. Gao, G. Chen, Heat conduction mechanisms in nanofluids and suspensions, Nano Today 7 (2) (2012) 124-136 https://doi.org/10. 1016/j.nantod.2012.02.007.

[30] K.V. Wong, M.J. Castillo, Heat transfer mechanisms and clustering in nanofluids, Adv. Mech. Eng. 2 (2015), https://doi.org/10.1155/2010/795478.
[31] E.I. Martín, A. Sánchez-Coronilla, J. Navas, R. Gómez Villarejo, J. Gallardo, R. Alcántara, C. Fernández-Lorenzo, Unraveling the role of the base fluid arrangement in metal-nanofluids used to enhance heat transfer in concentrating solar power plants, J. Mol. Liq. 252 (2018), https://doi.org/10.1016/j.molliq. 2017.12.153.

[32] J. Navas, A. Sánchez-Coronilla, E.I. Martín, M. Teruel, J. Gallardo, T. Aguilar, R. Gómez Villarejo, R. Alcántara, C. Fernández-Lorenzo, J. Piñero, J. MartínCalleja, On the enhancement of heat transfer fluid for concentrating solar power using $\mathrm{Cu}$ and $\mathrm{Ni}$ nanofluids: an experimental and molecular dynamics study, Nano Energy 27 (2016), https://doi.org/10.1016/j.nanoen.2016.07.004.

[33] S.A. Angayarkanni, J. Philip, Review on thermal properties of nanofluids: recent developments, Adv. Colloid Interface Sci. 225 (2015) 146-176 https://doi.org/10. 1016/j.cis.2015.08.014.

[34] W.S. Sarsam, S.N. Kazi, A. Badarudin, A review of studies on using nanofluids in flat-plate solar collectors, Sol. Energy 122 (2015) 1245-1265 https://doi.org/10. 1016/j.solener.2015.10.032.

[35] H. Jin, G. Lin, L. Bai, M. Amjad, E.P. Bandarra Filho, D. Wen, Photothermal conversion efficiency of nanofluids: an experimental and numerical study, Sol. Energy 139 (2016) 278-289 https://doi.org/10.1016/j.solener.2016.09.021.

[36] J. Philip, P.D. Shima, Thermal properties of nanofluids, Adv. Colloid Interface Sci. 183-184 (2012) 30-45 https://doi.org/10.1016/j.cis.2012.08.001.

[37] N. Chen, H. Ma, Y. Li, J. Cheng, C. Zhang, D. Wu, H. Zhu, Complementary optical absorption and enhanced solar thermal conversion of CuO-ATO nanofluids, Sol. Energy Mater. Sol. Cells 162 (2017) 83-92 https://doi.org/10.1016/j.solmat. 2016.12.049.

[38] M. Du, G.H. Tang, Plasmonic nanofluids based on gold nanorods/nanoellipsoids/ nanosheets for solar energy harvesting, Sol. Energy 137 (2016) 393-400 https:// doi.org/10.1016/j.solener.2016.08.029.

[39] F. Kiliç, T. Menlik, A. Sözen, Effect of titanium dioxide/water nanofluid use on thermal performance of the flat plate solar collector, Sol. Energy 164 (2018) 101-108 https://doi.org/10.1016/j.solener.2018.02.002.

[40] X. Li, C. Zou, W. Chen, X. Lei, Experimental investigation of $\beta$-cyclodextrin modified carbon nanotubes nanofluids for solar energy systems: stability, optical properties and thermal conductivity, Sol. Energy Mater. Sol. Cells 157 (2016) 572-579 https://doi.org/10.1016/j.solmat.2016.07.030.

[41] X. Yu, Y. Xuan, Investigation on thermo-optical properties of $\mathrm{CuO} / \mathrm{Ag}$ plasmonic nanofluids, Sol. Energy 160 (2018) 200-207 https://doi.org/10.1016/j.solener. 2017.12.007.

[42] A. Zeiny, H. Jin, L. Bai, G. Lin, D. Wen, A comparative study of direct absorption nanofluids for solar thermal applications, Sol. Energy 161 (2018) 74-82 https:// doi.org/10.1016/j.solener.2017.12.037.

[43] W. Chamsa-Ard, S. Brundavanam, C.C. Fung, D. Fawcett, G. Poinern, Nanofluid types, their synthesis, properties and incorporation in direct solar thermal collectors: a review, Nanomaterials (Basel) 7 (6) (2017), https://doi.org/10.3390/ nano7060131.

[44] H.A. Mintsa, G. Roy, C.T. Nguyen, D. Doucet, New temperature dependent thermal conductivity data for water-based nanofluids, Int. J. Therm. Sci. 48 (2) (2009) 363-371 https://doi.org/10.1016/j.ijthermalsci.2008.03.009.

[45] S.M.S. Murshed, K.C. Leong, C. Yang, Enhanced thermal conductivity of TiO2-water based nanofluids, Int. J. Therm. Sci. 44 (4) (2005) 367-373 https:// doi.org/10.1016/j.ijthermalsci.2004.12.005.

[46] X. Zhang, H. Gu, M. Fujii, Experimental study on the effective thermal conductivity and thermal diffusivity of nanofluids, Int. J. Thermophys. 27 (2) (2006) 569-580 https://doi.org/10.1007/s10765-006-0054-1.

[47] D.W. Jing, D.X. Song, Optical properties of nanofluids considering particle size distribution: experimental and theoretical investigations, Renew. Sustain. Energy Rev. 78 (2017) 452-465 https://doi.org/10.1016/j.rser.2017.04.084.

[48] Y. Wu, L.P. Zhou, X.Z. Du, Y.P. Yang, Optical and thermal radiative properties of plasmonic nanofluids containing core-shell composite nanoparticles for efficient photothermal conversion, Int. J. Heat Mass Transf. 82 (2015) 545-554 https://doi. org/10.1016/j.ijheatmasstransfer.2014.11.026.

[49] H.D. Beyene, A.A. Werkneh, H.K. Bezabh, T.G. Ambaye, Synthesis paradigm and applications of silver nanoparticles (AgNPs), a review, Sustainable Materials and Technologies 13 (2017) 18-23 https://doi.org/10.1016/j.susmat.2017.08.001.

[50] M. Chen, Y. He, J. Zhu, Y. Shuai, B. Jiang, Y. Huang, An experimental investigation on sunlight absorption characteristics of silver nanofluids, Sol. Energy 115 (2015) 85-94 https://doi.org/10.1016/j.solener.2015.01.031.

[51] S. Iyahraja, J.S. Rajadurai, Study of thermal conductivity enhancement of aqueous suspensions containing silver nanoparticles, AIP Adv. 5 (5) (2015), https://doi. org/10.1063/1.4919808.

[52] H.E. Patel, S.K. Das, T. Sundararajan, A. Sreekumaran Nair, B. George, T. Pradeep, Thermal conductivities of naked and monolayer protected metal nanoparticle based nanofluids: manifestation of anomalous enhancement and chemical effects, Appl. Phys. Lett. 83 (14) (2003) 2931-2933 https://doi.org/10.1063/1.1602578.

[53] M. Seyhan, C.L. Altan, B. Gurten, S. Bucak, The effect of functionalized silver nanoparticles over the thermal conductivity of base fluids, AIP Adv. 7 (4) (2017) https://doi.org/10.1063/1.4979554.

[54] N.G. Bastús, F. Merkoçi, J. Piella, V. Puntes, Synthesis of highly monodisperse citrate-stabilized silver nanoparticles of up to $200 \mathrm{~nm}$ : kinetic control and catalytic properties, Chem. Mater. 26 (9) (2014) 2836-2846 https://doi.org/10.1021/ cm500316k.

[55] K.L. Kelly, E. Coronado, L.L. Zhao, G.C. Schatz, The optical properties of metal Nanoparticles: the influence of size, shape, and dielectric environment, J. Phys. Chem. B 107 (3) (2003) 668-677 https://doi.org/10.1021/jp026731y.

[56] B. Khodashenas, H.R. Ghorbani, Synthesis of silver nanoparticles with different shapes, Arab.J. Chem. (2015), https://doi.org/10.1016/j.arabjc.2014.12.014. 
[57] L.M. Liz-Marzán, Nanometals: formation and color, Mater. Today 7 (2) (2011) 26-31 https://doi.org/10.1016/S1369-7021(04)00080-X.

[58] S.U. Ilyas, R. Pendyala, N. Marneni, Preparation, sedimentation, and agglomeration of nanofluids, Chem. Eng. Technol. 37 (12) (2014) 2011-2021 https://doi. org/10.1002/ceat.201400268.

[59] R. Azizian, E. Doroodchi, B. Moghtaderi, Influence of controlled aggregation on thermal conductivity of nanofluids, J. Heat Transf. 138 (2) (2015), https://doi. org $/ 10.1115 / 1.4031730$.

[60] C. Pang, J.-Y. Jung, Y.T. Kang, Aggregation based model for heat conduction mechanism in nanofluids, Int. J. Heat Mass Transf. 72 (2014) 392-399 https://doi. org/10.1016/j.ijheatmasstransfer.2013.12.055.

[61] L. Chen, C. Xu, J. Liu, X. Fang, Z. Zhang, Optical absorption property and photothermal conversion performance of graphene oxide/water nanofluids with excellent dispersion stability, Sol. Energy 148 (2017) 17-24 https://doi.org/10. 1016/j.solener.2017.03.073.

[62] S. Mesgari, R.A. Taylor, N.E. Hjerrild, F. Crisostomo, Q. Li, J. Scott, An investigation of thermal stability of carbon nanofluids for solar thermal applications, Sol. Energy Mater. Sol. Cells 157 (2016) 652-659 https://doi.org/10.1016/j. solmat.2016.07.032.

[63] Q. Zhang, W. Xu, X. Wang, Carbon nanocomposites with high photothermal conversion efficiency, Sci.China. Mater. 61 (7) (2018) 905-914 https://doi.org/ 10.1007/s40843-018-9250-x.

[64] E.V. Timofeeva, J.L. Routbort, D. Singh, Particle shape effects on thermophysical properties of alumina nanofluids, J. Appl. Phys. 106 (1) (2009), https://doi.org/ 10.1063/1.3155999.

[65] J. Qu, M. Tian, X. Han, R. Zhang, Q. Wang, Photo-thermal conversion characteristics of MWCNT-H2O nanofluids for direct solar thermal energy absorption applications, Appl. Therm. Eng. 124 (2017) 486-493 https://doi.org/10.1016/j. applthermaleng.2017.06.063.

[66] G. Sun, J.B. Khurgin, Comparative study of field enhancement between isolated and coupled metal nanoparticles: an analytical approach, Appl. Phys. Lett. 97 (26) (2010), https://doi.org/10.1063/1.3532101.

[67] G. Sun, J.B. Khurgin, Theory of optical emission enhancement by coupled metal nanoparticles: an analytical approach, Appl. Phys. Lett. 98 (11) (2011), https:// doi.org/10.1063/1.3565170.

[68] G. Sun, J.B. Khurgin, A. Bratkovsky, Coupled-mode theory of field enhancement in complex metal nanostructures, Phys. Rev. B 84 (4) (2011) 045415https://doi.org/ 10.1103/PhysRevB.84.045415.

[69] G. Sun, J.B. Khurgin, C.C. Yang, Impact of high-order surface plasmon modes of metal nanoparticles on enhancement of optical emission, Appl. Phys. Lett. 95 (17) (2009), https://doi.org/10.1063/1.3250160.

[70] M. Amjad, H. Jin, X. Du, D. Wen, Experimental photothermal performance of nanofluids under concentrated solar flux, Sol. Energy Mater. Sol. Cells 182 (2018) 255-262 https://doi.org/10.1016/j.solmat.2018.03.044.

[71] X. Wang, Y. He, M. Chen, Y. Hu, ZnO-Au composite hierarchical particles dispersed oil-based nanofluids for direct absorption solar collectors, Sol. Energy Mater. Sol. Cells 179 (2018) 185-193 https://doi.org/10.1016/j.solmat.2017.11. 012.

[72] D. Chauhan, N. Singhvi, R. Singh, Effect of geometry of filler particles on the effective thermal conductivity of two-phase systems, Int. J. Mod. Nonlinear Theory Appl. 01 (02) (2012) 40-46 https://doi.org/10.4236/ijmnta.2012.12005.

[73] C. Liu, M. Chen, D. Zhou, D. Wu, W. Yu, Effect of filler shape on the thermal conductivity of thermal functional composites, J. Nanomater. 2017 (2017) 1-15 https://doi.org/10.1155/2017/6375135.

[74] J.A. Ranga Babu, K.K. Kumar, S. Srinivasa Rao, State-of-art review on hybrid nanofluids, Renew. Sustain. Energy Rev. 77 (2017) 551-565 https://doi.org/10. 1016/j.rser.2017.04.040.

[75] P. Van Trinh, N.N. Anh, B.H. Thang, L.D. Quang, N.T. Hong, N.M. Hong, P.H. Khoi, P.N. Minh, P.N. Hong, Enhanced thermal conductivity of nanofluid-based ethylene glycol containing Cu nanoparticles decorated on a Gr-MWCNT hybrid material, RSC Adv. 7 (1) (2017) 318-326 https://doi.org/10.1039/C6RA25625B.

[76] W. Yu, J. Zhao, M. Wang, Y. Hu, L. Chen, H. Xie, Thermal conductivity enhancement in thermal grease containing different $\mathrm{CuO}$ structures, Nanoscale.Res. Lett. 10 (1) (2015), https://doi.org/10.1186/s11671-015-0822-6.

[77] A. Power, The Preparation and Characterisation of Silver Nanomaterials and Their Application in Sensing Technique, Doctoral Thesis Dublin Institute of Technology, 2011, https://doi.org/10.21427/D7M88K.

[78] A.C. Power, A.J. Betts, J.F. Cassidy, Silver nanoparticle polymer composite based humidity sensor, Analyst 135 (7) (2010) 1645-1652 https://doi.org/10.1039/ COAN00133C.

[79] A.C. Power, A.J. Betts, J.F. Cassidy, Non aggregated colloidal silver nanoparticles for surface enhanced resonance Raman spectroscopy, Analyst 136 (13) (2011) 2794-2801 https://doi.org/10.1039/c1an15250e.

[80] L. Antonov, D. Nedeltcheva, Resolution of overlapping UV-Vis absorption bands and quantitative analysis, Chem. Soc. Rev. 29 (3) (2000) 217-227 https://doi.org/ $10.1039 / \mathrm{A} 900007 \mathrm{~K}$.

[81] T. Owen, Fundamentals of UV-Visible Spectroscopy, A Primer. Agilent Technologies, 2000.

[82] B.H. Stuart, Infrared Spectroscopy: Fundamentals and Applications, Wiley, 2004.

[83] ASTM-G173-03, Standard Tables for Reference Solar Spectral Irradiances: Direct
Normal and Hemispherical on $37^{\circ}$ Tilted Surface, ASTM International, 2012.

[84] M. Chen, Y. He, J. Zhu, D. Wen, Investigating the collector efficiency of silver nanofluids based direct absorption solar collectors, Appl. Energy 181 (2016) 65-74 https://doi.org/10.1016/j.apenergy.2016.08.054.

[85] H. Zhang, H.-J. Chen, X. Du, D. Wen, Photothermal conversion characteristics of gold nanoparticle dispersions, Sol. Energy 100 (2014) 141-147 https://doi.org/ 10.1016/j.solener.2013.12.004.

[86] P. Keblinski, D.G. Cahill, A. Bodapati, C.R. Sullivan, T.A. Taton, Limits of localized heating by electromagnetically excited nanoparticles, J. Appl. Phys. 100 (5) (2006), https://doi.org/10.1063/1.2335783.

[87] E. Allahyarov, K. Sandomirski, S.U. Egelhaaf, H. Lowen, Crystallization seeds favour crystallization only during initial growth, Nat. Commun. 6 (2015) 7110 https://doi.org/10.1038/ncomms8110.

[88] A. Cacciuto, S. Auer, D. Frenkel, Onset of heterogeneous crystal nucleation in colloidal suspensions, Nature 428 (2004) 404 https://doi.org/10.1038/ nature02397.

[89] X. Deng, Z. Huang, W. Wang, R.N. Davé, Investigation of nanoparticle agglomerates properties using Monte Carlo simulations, Adv. Powder Technol. 27 (5) (2016) 1971-1979 https://doi.org/10.1016/j.apt.2016.06.029.

[90] B.J. Wiley, S.H. Im, Z.-Y. Li, J. McLellan, A. Siekkinen, Y. Xia, Maneuvering the surface plasmon resonance of silver nanostructures through shape-controlled synthesis, J. Phys. Chem. B 110 (32) (2006) 15666-15675 https://doi.org/10. 1021/jp0608628.

[91] J. Olson, S. Dominguez-Medina, A. Hoggard, L.Y. Wang, W.S. Chang, S. Link, Optical characterization of single plasmonic nanoparticles, Chem. Soc. Rev. 44 (1) (2015) 40-57 https://doi.org/10.1039/C4CS00131A.

[92] E. Ringe, R.P.V. Duyne, L.D. Marks, Correlated structure-optical properties studie of plasmonic nanoparticles, J. Phys. Conf. Ser. 522 (2014), https://doi.org/10. 1088/1742-6596/522/1/012006.

[93] S. Bhattacharjee, DLS and zeta potential - what they are and what they are not? J. Control. Release 235 (2016) 337-351 https://doi.org/10.1016/j.jconrel.2016.06. 017.

[94] K.B. Hadjov, D.P. Dontchev, Influence of the particle size distribution on the thermal conductivity of nanofluids, J. Nanoparticle Res. 11 (7) (2009) 1713-1718 https://doi.org/10.1007/s11051-008-9539-0.

[95] H. Xie, J. Wang, T. Xi, Y. Liu, F. Ai, Q. Wu, Thermal conductivity enhancement of suspensions containing nanosized alumina particles, J. Appl. Phys. 91 (7) (2002) 4568-4572 https://doi.org/10.1063/1.1454184.

[96] K.M. Powell, K. Rashid, K. Ellingwood, J. Tuttle, B.D. Iverson, Hybrid concentrated solar thermal power systems: a review, Renew. Sustain. Energy Rev. 80 (2017) 215-237 https://doi.org/10.1016/j.rser.2017.05.067.

[97] V. Siva Reddy, S.C. Kaushik, K.R. Ranjan, S.K. Tyagi, State-of-the-art of solar thermal power plants-a review, Renew. Sustain. Energy Rev. 27 (2013) 258-273 https://doi.org/10.1016/j.rser.2013.06.037.

[98] A.R. Mallah, S.N. Kazi, M.N.M. Zubir, A. Badarudin, Blended morphologies of plasmonic nanofluids for direct absorption applications, Appl. Energy 229 (2018) 505-521 https://doi.org/10.1016/j.apenergy.2018.07.113.

[99] J. Sui, P. Zhao, B. Bin-Mohsin, L. Zheng, X. Zhang, Z. Cheng, Y. Chen, G. Chen, Fractal aggregation kinetics contributions to thermal conductivity of nano-suspensions in unsteady thermal convection, Sci. Rep. 6 (2016) 39446 https://doi org $/ 10.1038 /$ srep39446.

[100] D.A. Weitz, J.S. Huang, M.Y. Lin, J. Sung, Limits of the fractal dimension for irreversible kinetic aggregation of gold colloids, Phys. Rev. Lett. 54 (13) (1985) 1416-1419 https://doi.org/10.1103/PhysRevLett.54.1416.

[101] R. Prasher, P. Bhattacharya, P.E. Phelan, Thermal conductivity of nanoscale colloidal solutions (nanofluids), Phys. Rev. Lett. 94 (2) (2005) 025901https://doi. org/10.1103/PhysRevLett.94.025901.

[102] C.H. Li, G.P. Peterson, The effect of particle size on the effective thermal conductivity of Al2O3-water nanofluid, J. Appl. Phys. 101 (4) (2007) p. 044312 https://doi.org/10.1063/1.2436472.

[103] G.M. Hale, M.R. Querry, Optical constants of water in the 200-nm to $200-\mu \mathrm{m}$ wavelength region, Appl. Opt. 12 (3) (1973) 555-563 https://doi.org/10.1364/ AO.12.000555.

[104] S. Teerasong, A. Jinnarak, S. Chaneam, P. Wilairat, D. Nacapricha, Poly(vinyl alcohol) capped silver nanoparticles for antioxidant assay based on seed-mediated nanoparticle growth, Talanta 170 (2017) 193-198 https://doi.org/10.1016/j . talanta.2017.04.009.

[105] R.D. Selvakumar, S. Dhinakaran, A multi-level homogenization model for thermal conductivity of nanofluids based on particle size distribution (PSD) analysis, Powder Technol. 301 (2016) 310-317 https://doi.org/10.1016/j.powtec.2016.05. 049.

[106] Q. Yu, P. Weng, L. Han, X. Yin, Z. Chen, X. Hu, L. Wang, H. Wang, Enhanced thermal conductivity of flexible cotton fabrics coated with reactive MWCNT nanofluid for potential application in thermal conductivity coatings and fire warning, Cellulose (2019), https://doi.org/10.1007/s10570-019-02592-w In press.

[107] Z. Sang, W. Zhang, Z. Zhou, H. Fu, Y. Tan, K. Sui, Y. Xia, Functionalized alginate with liquid-like behaviors and its application in wet-spinning, Carbohydrate Polymers (2017) 933-940, https://doi.org/10.1016/j.carbpol.2017.07.027. 